\title{
Glucocorticoid receptor activities in the zebrafish model: a review
}

\author{
Alberto Dinarello*, Giorgio Licciardello*, Camilla Maria Fontana, Natascia Tiso(D), Francesco Argenton* and \\ Luisa Dalla Valle* \\ Department of Biology, University of Padova, Padova, Italy
}

Correspondence should be addressed to F Argenton or L Dalla Valle: francesco.argenton@unipd.it or luisa.dallavalle@unipd.it

*(A Dinarello, G Licciardello, F Argenton and L Dalla Valle contributed equally to this work)

\begin{abstract}
Glucocorticoids (GCS) are steroid hormones that contribute to the regulation of many physiological processes, such as inflammation, metabolism and stress response, mainly through binding to their cognate receptor, GR, which works as a ligand-activated transcription factor. Due to their pleiotropy and the common medical use of these steroids to treat patients affected by different pathologies, the investigation of their mechanisms of action is extremely important in biology and clinical research. The evolutionary conservation of GC physiological function, biosynthesis pathways, as well as the sequence and structure of the GC nuclear receptors has stimulated, in the last 20 years, the use of zebrafish (a teleost of Cyprinidae family) as a reliable model organism to investigate this topic. In this review, we wanted to collect many of the most significant findings obtained by the the scientific community using zebrafish to study GCs and their receptors. The paper begins by describing the experiments with transient knockdown of zebrafish gr to gain insights, mainly during development, and continues with the discoveries provided by the generation of transgenic reporter lines. Finally, we discuss how the generation of mutant lines for either gr or the enzymes involved in GC synthesis has significantly advanced our knowledge on GC biology.
\end{abstract}

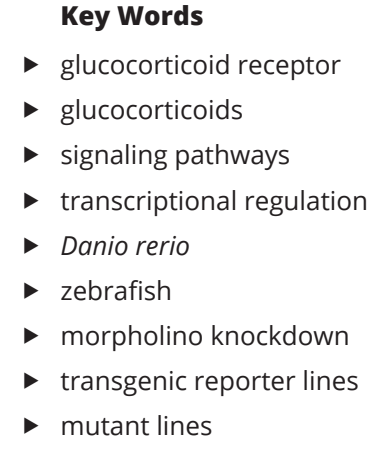

Journal of Endocrinology (2020) 247, R63-R82

\section{The glucocorticoid signaling pathways}

Steroid hormones are lipophilic and low-molecular weight compounds broadly involved in endocrine signaling, thus, able to trigger systemic effects through bloodstream circulation. All steroid hormones derive from cholesterol, whose basic structure is cyclopentanoperhydrophenanthrene, a molecule characterized by a core containing 17 carbon atoms fused to form four rings. Specific functional groups attached to these rings determine the precise chemical properties of the different steroids.

These hormones can be grouped into two main classes: corticosteroids and sex steroids, according to their major site of synthesis and function. Particularly, corticosteroids include glucocorticoids (GCs) (corticosterone, 11-dehydrocorticosterone, cortisol, and cortisone) and mineralocorticoids (aldosterone, 11-deoxycorticosterone), while sex steroids include androgens (androstenedione, testosterone, $5 \alpha$-dihydrotestosterone), estrogens (estrone, estradiol), and progestogens (progesterone).

In humans, biosynthesis and release of GCs predominantly take place in adrenal cortex where it is regulated by the hypothalamus-pituitary-adrenal (HPA or hypothalamus-pituitary-interrenal, HPI, in fish) neuroendocrine axis. Moreover, local GC synthesis also 
occurs in different tissues, including lymphoid organs, skin, brain, intestine and cardiovascular system (Taves et al. 2011).

GCs mainly exert their systemic functions through the binding to the glucocorticoid receptor (GR) and the mineralocorticoid receptor (MR). Due to their steroid lipophilic nature, GCs can cross cell membranes and bind their intracellular receptors. GR resides in the cytoplasm in almost all mammalian tissues and is involved in a wide spectrum of different systemic effects, such as growth, reproduction, bone formation, vascular tone, brain functions and immune response (Nicolaides et al. 2010). In humans, GR is translated from a single gene, termed NR3C1, while different protein isoforms are generated by various mechanisms, such as alternative splicing, alternative translation initiation, and posttranslational modifications (ubiquitination, SUMOylation, phosphorylation, acetylation) (Oakley \& Cidlowski 2013). In more detail, the hNR3C1 gene is located on chromosome 5 and consists of nine exons. The alternative splicing of exon 9 results in the production of two different mRNAs coding for either the $\alpha$ or $\beta$ isoform. At their C-terminal, after a common sequence of 727 amino acids (aa), the $\alpha$ and $\beta$ isoforms display a stretch of 50 and 15 non-homologous aa, respectively. While hGR $\alpha$ is a cytosolic protein having the classical functions of a GC cognate receptor, the hGR $\beta$ roles are not completely understood: the protein is unable to bind GCs and is thought to exert its activity as a dominantnegative inhibitor of GR $\alpha$ (Nicolaides et al. 2010, Quax et al. 2013). Additionally, GRo-independent, genespecific transcriptional activities have been described for GR $\beta$, at least in in vitro models (Lewis-Tuffin et al. 2007, Kino et al. 2009).

Evolutionary analysis revealed that all members of the steroid receptor family derive from a single ancestral estrogen receptor (ER) and share the same modular structure (Eick \& Thornton 2011).

Accordingly, the N-terminal portion of GR contains a transactivation domain (NTD) followed by the two zinc-finger motifs of the DNA binding domain (DBD). The carboxy-terminal domain, that is separated by a hinge region from the DBD, contains the GC binding site (LBD) and a second region with activation functions (AF2) (Kadmiel \& Cidlowski 2013). In the absence of ligands, inactive GR is stuck in the cytoplasm, forming a multimeric complex with other proteins, including heat shock protein (HSP) 90, HSP70 and immunophilins, and is unable to promote any genomic effect. Upon binding with the ligand, GR was assumed to dissociate from the repressor protein complex and migrate to the nucleus to regulate gene transcription. This classical view of GC action has recently been revised and described as a more complicated process in which, after binding with GCs, the composition of the multimeric complex changes: immunophilin FKBP51 (FK506-binding protein 51), a co-chaperone protein that binds HSP90 and decreases the affinity of GR for cortisol, is replaced by FKBP52 (FK506-binding protein 52), recruiting dynein to support translocation of the GC/GR complex to the nucleus (Binder 2009). Finally, the heterocomplex between GR and HSP90, enter through the nuclear pore complex and dissociates when inside the nucleus (reviewed by Daneri-Becerra et al. 2019) (Fig. 1).

Once into the nucleus, either in a monomeric or dimeric form, the GC/GR complex is able to modulate gene expression in different ways: either by direct binding to DNA, or by tethering to other DNA-bound transcription factors, or in a composite manner that requires direct interaction with DNA and adjacent DNAbound transcription factors (Oakley \& Cidlowski 2013). The overall effect of these interactions may result in the stimulation or repression of gene transcription (Kadmiel \& Cidlowski 2013) (Fig. 1). GR is able to bind glucocorticoid response elements (GREs) consisting of palindromic 5'-GGTACAnnnTGTTCT-3' DNA sequences, in which ' $n$ ' could be any nucleotide (Beato \& Klug 2000). Remarkably, the response elements of other steroid receptors that share with GR the same common ancestor and conformational similarities, such as androgen receptor (AR), progestin receptor (PR), and mineralocorticoid receptor (MR), show strong resemblance, despite their different genetic, genomic and physiological functions (Beato \& Klug 2000, Geserick et al. 2005). Because of this promiscuity, some authors refer to GREs as hormone responsive elements (HREs) (Beato \& Klug 2000). The specificity of the response relies on several factors like cell-specific expression (this is not always the case), tethering with other transcriptional regulatory elements (co-factors) as well as co-activators (Geserick et al. 2005, van Weert et al. 2017), variation of the DNA binding sequence as well as specific contact of the receptors with the flanking regions (reviewed in Veras Ribeiro Filho et al. 2019). This allows that, despite strong similarities in their responsive elements, co-expression and activity of different receptors in the same cell can result, in combination with each other and with other transcription factors, in the transcriptional regulation of different genes (Severson et al. 2018).

Pieces of evidence also suggest that GCs can exert some of their functions by non-genomic rapid response mediated by either membrane-bound GR 


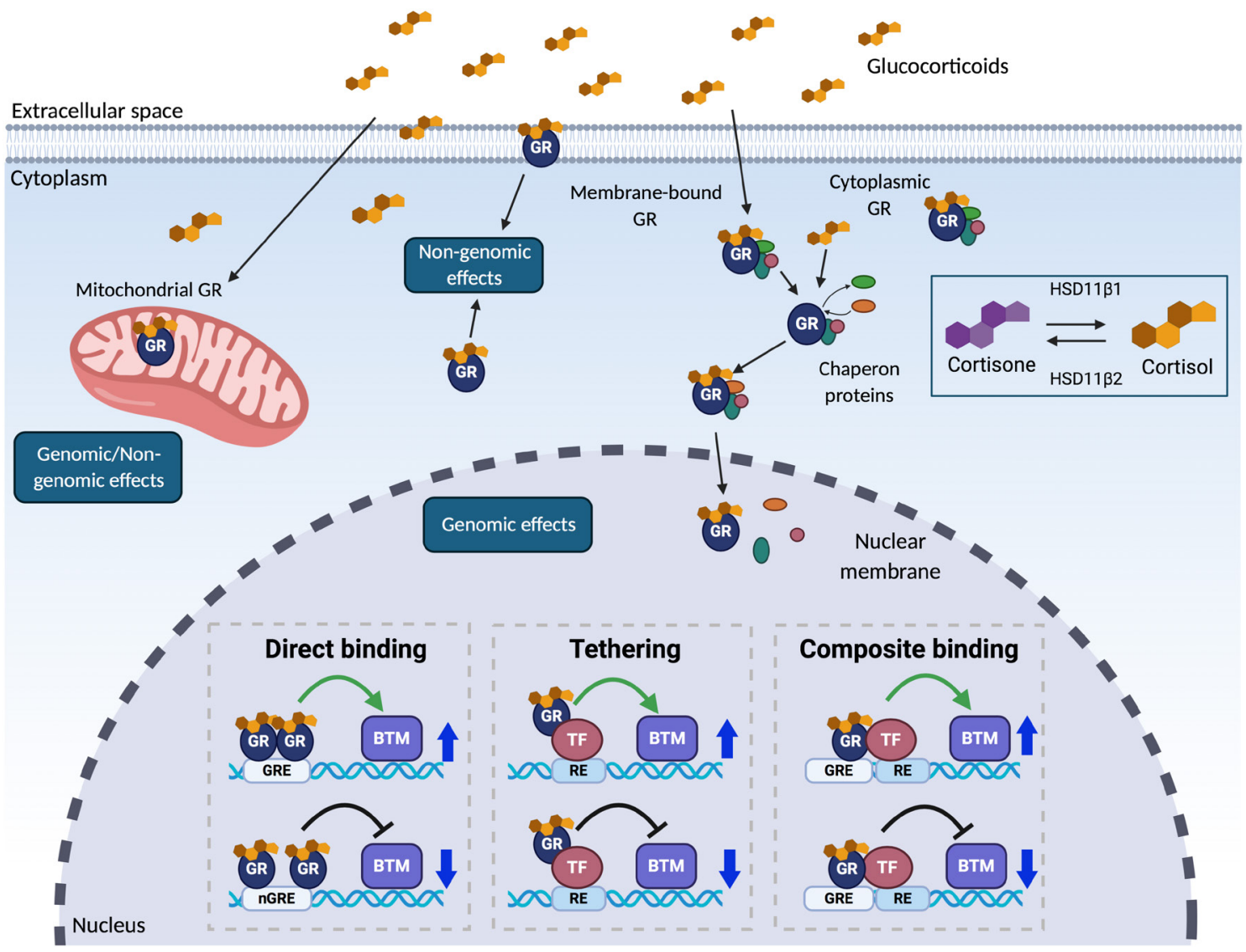

\section{Figure 1}

Glucocorticoid genomic and non-genomic signaling. GCs are small lipophilic molecules that are able to cross membranes and trigger a plethora of different and partially unrevealed molecular responses. GCs may bind cytoplasmic or membrane GR to exert their rapid, non-genomic biological function interacting with other proteins or shifting their localization to the mitochondria. Mechanisms of enzymatic cytosolic inactivation or reactivation of GCs operated by $11 \beta$-hydroxysteroid dehydrogenase type 1 and type 2, may regulate GC viability. In the absence of ligands, inactive GR is located in the cytoplasm, forming an inactive multimeric complex with other proteins. Upon binding with the ligand, the immunophilin FKBP51 is replaced by FKBP52, which recruits dynein motors and allows GC/GR translocation to the nucleus where GR dissociates from HSP90. The genomic response may act through at least three different mechanisms: direct binding in which GC/GR can bind DNA elements, functioning as positive (GRE) or negative (nGRE) regulation elements; tethering in which GC/GR may physically interact with other transcription factors to regulate gene expression and composite binding in which GC/GR requires both GRE elements and physical interaction with other transcription factors to exert its transcriptional activity. BTM: basal transcription machinery.

(Groeneweg et al. 2012, Scheschowitsch et al. 2017) or direct interactions with different kinases, such as protein kinase $\mathrm{B}$ (PKB), phosphoinositide 3-kinase (PI3K), and mitogen-activated protein kinases (MAPKs) (Oakley \& Cidlowski 2013). Additionally, after binding to GCs, $\mathrm{GR} \alpha$ can translocate into mitochondria and regulate mitochondrial transcription (Lapp et al. 2019) (Fig. 1).

In mammals, as expected by the almost ubiquitous expression of their receptor, GCs regulate many physiological processes, including metabolic homeostasis, immune system, reproduction, behavior and stress response (Whirledge \& DeFranco 2018).

The employment of $G R$ mutant mouse $\left(G R^{-/-}\right)$, obtained by homologous recombination, demonstrated that GCs are required for correct development and organogenesis (Cole et al. 1995). This mutant line was crucial to determine how liver, adrenal gland, brain, and HPA axis are affected by GR knockout during development (Cole et al. 1995, Schmid et al. 1995). On the other hand, $G R^{-/-}$mice die within a few hours after birth, due to lung insufficiency and respiratory failure; this represents a major limitation of the $\mathrm{KO}$ mouse model (Cole et al. 1995). Taken together, these results suggest that GC signaling pathways, while playing a pivotal role in postnatal life, are also essential during development. However, the KO mouse model is not informative enough to satisfactorily elucidate the role of GR functions in the early phases of embryonic development, mostly because of the inaccessibility to the mouse embryo. Yet, it is not possible to explore the signaling pathway in adulthood either, because of the premature death for lung insufficiency. 
Therefore, conditional and inducible $\mathrm{KO}$ mice were produced to study the relevance of GC signaling pathways in a physiological context (recently reviewed by Whirledge \& DeFranco 2018). For example, GR was specifically deleted in the brain, revealing that the absence of this signaling in the CNS leads to reduced anxiety-related behavior, thus highlighting the role of GCs as a behavioral modulator (Tronche et al. 1999). As reported by Whirledge \& DeFranco (2018), conditional mice were generated to characterize specific functions of GR in numerous cell types, sometimes with contradictory data, possibly due to different experimental approaches and genetic background of mouse strains. These models are extremely important for the functional analysis of GR signaling in specific tissues and cell types, although the possibility to analyze GR null models is desirable since alteration in GC concentration leads to responses at the global level of an organism.

GC imbalance is associated with pathological conditions. GC chronic increase or decrease can result in complex endocrine disorders involving the adrenal cortex and are known as Cushing's and Addison's disease, respectively (Kadmiel \& Cidlowski 2013). An excess of cortisol, along with bone loss, metabolic diseases and high blood pressure, is linked with distinctive changes in physical appearance; patients who are affected by Cushing's disease are more likely to develop cardiovascular diseases (Fardet et al. 2012). On the other hand, since Addison's disease is due to lack of cortisol and aldosterone production by the adrenal gland, people affected by this disease are characterized by low blood pressure, hyperpigmentation and muscle weakness (Napier \& Pearce 2014). Moreover, abnormally high levels of GCs are found to be associated with psychiatric diseases, such as schizophrenia, mood disorders and post-traumatic stress disorders (Silverman \& Sternberg 2012), as well as drug and alcohol dependence (Ambroggi et al. 2009).

Interestingly, synthetic GCs, being able to inhibit pro-inflammatory transcription factor like nuclear factor $\kappa$-light-chain-enhancer of activated B cells $(\mathrm{NF}-\kappa \mathrm{B})$ and promoting anti-inflammatory genes such as the interleukin 10 (IL-10), are widely administered as therapeutic compounds to contrast inflammation and other symptoms of autoimmune disorders or lymphoproliferative diseases (Yasir et al. 2020).

Cortisone was first administered for therapeutic purposes in the late '40s by Philip Hench. The physician, who used it to treat the inflammation due to rheumatoid arthritis, was later awarded the Nobel prize for Physiology or Medicine in 1950 (Burns 2016).
On the other hand, GC-based therapies may carry some adverse effects that should not be neglected: premature arteriosclerosis, arrhythmias, gastric ulcers, glaucomas, cushingoid features (Yasir et al. 2020).

\section{The study of GC/GR signaling in Danio rerio}

The wide implications of GCs in physiological and pathological conditions make their signaling a fascinating field of scientific research. The difficulties encountered in mammalian models, such as the limited number of offspring, the inaccessibility of the mouse embryos and the impossibility of raising $G R^{-/-}$mice to adulthood, can be overtaken by broadening the model species used to study these hormones.

Zebrafish (D. rerio), a freshwater fish, is largely employed as a model organism in scientific research for its intrinsic properties, such as abundance of offspring, external fertilization and development, remarkable optical accessibility of embryo at any developmental stage from fertilization. In addition, $D$. rerio shares extensive genetic, physiological and molecular similarities with mammals, features that make it an excellent model for developmental studies (Balasubramanian et al. 2019), drug discovery (MacRae \& Peterson 2015), cancer biology (Lobert et al. 2016), ecotoxicology (Bambino \& Chu 2017), as well as endocrinology and GC/Gr research (McGonnell \& Fowkes 2006, Schaaf et al. 2009, Löhr \& Hammerschmidt 2011).

Despite a high conservation between zebrafish and human of the main steroidogenic pathways, suggesting a general conservation of the molecular and cellular processes, some differences are evident, particularly concerning the synthesis of some teleost-specific steroids (Tokarz et al. 2015). The mineralocorticoid receptor $(\mathrm{Mr})$ is present in teleosts but is activated by 11-deoxycorticosterone and cortisol (Pippal et al. 2011). Aldosterone, the main mammalian mineralocorticoid, is not synthetized in teleosts and is a synapomorphic trait of the tetrapods clade, needed to maintain ion balance after the transition from the water to the land (Colombo et al. 2006, Tokarz et al. 2015, Baker 2019). In addition, a notable difference between teleost and mammals is the anatomical location of the GC secreting cells. In most teleosts, including zebrafish, the interrenal cells involved in GC synthesis is interspersed throughout the head kidney. Hence, the axis that regulates GC synthesis is called HPI (Alsop \& Vijayan 2009, Löhr \& Hammerschmidt 2011). 
Despite the genome duplication occurred in the teleost clade (Volff et al. 2005), zebrafish carries a single copy of the $g r$ gene ( $n r 3 c 1)$, located on chromosome 14, while the second copy has possibly been lost recently, likely as a consequence of chromosome 21 rearrangements (Schaaf et al. 2008). The human and zebrafish genes for GR show remarkable similarities in their structure, including an alternative splice variant processing leading, also in zebrafish, to a Gr $\beta$ isoform (Schaaf et al. 2008). However, recent studies suggest that, at least in zebrafish, the Gr $\beta$ isoform is not involved in transcriptional regulation (Chatzopoulou et al. 2017).

The aim of this review is to highlight how zebrafish models were employed to elucidate the molecular pathways underlying the GC-activated signaling and show how the endocrinological field may further benefit from studies in $D$. rerio.

\section{Morpholino-induced knockdown of glucocorticoid receptors in zebrafish}

Zebrafish fertilization, being external, allows the microinjection of small antisense oligomers, called morpholinos (MOs), to transiently inhibit the function of target genes by hampering either translation (ATG-MO) or splicing (SPL-MO) of their mRNA. Since the early 2000s, this practice has been the most common to overcome the lack of efficient, targeted mutagenesis methods in zebrafish (Stainier et al. 2017) (Fig. 2).

\begin{tabular}{|c|c|c|}
\hline one-cell embryo & $\begin{array}{l}\text { Transient depletion } \\
\text { of } \mathrm{Gr}\end{array}$ & $\rightarrow \begin{array}{c}\text { Transient } \\
\text { knockdown }\end{array}$ \\
\hline Results & Source & Morpholino \\
\hline $\begin{array}{l}\text { Fin regeneration: } \\
\mathrm{GCS} \text { are involved in fin regeneration inhibition } \\
\text { cripto1 is a } \mathrm{Gr} \text { target gene in the regulation of } \\
\text { regeneration process }\end{array}$ & $\begin{array}{l}\text { Mathew et al. (2007) } \\
\text { Garland et al. (2019) }\end{array}$ & $g r^{\text {spli }} \mathrm{MOs}$ \\
\hline $\begin{array}{l}\text { Development: } \\
\text { Maternal } g r \text { is crucial for correct development } \\
\text { Gr controls mesoderm formation, muscle, heart, eye } \\
\text { development and BMP pathway } \\
\text { Gr knockdown reduces embryonic hematopoietic stem } \\
\text { and progenitor cell. } \\
\text { gr knockdown affects larvae and adult behaviour, } \\
\text { hatching, metabolism, HPI axis as well as heart } \\
\text { development }\end{array}$ & $\begin{array}{l}\text { Pikulkaew et al. (2011) } \\
\text { Nesan et al. (2012) } \\
\text { Nesan \& Vijayan (2013) } \\
\text { Kwan et al. (2016) } \\
\text { Wilson et al. (2015) } \\
\text { Wilson et al. (2016) }\end{array}$ & $\begin{array}{l}g r^{A T G} \mathrm{MOs} \\
g r^{\text {splic }} \mathrm{MOs}\end{array}$ \\
\hline $\begin{array}{l}\text { Ion balance: } \\
\text { Cortisol affects sodium uptake in zebrafish larvae, } \\
\text { regulates differentiation of epidermal ionocytes and } \\
\text { expression of membrane transporters through } \mathrm{Gr} \\
\text { Gills and embryonic skin sodium transporters expression } \\
\text { are regulated by } \mathrm{Gr} \text { but not by } \mathrm{Mr} \\
\text { Cortisol regulates epithelial permeability and } \mathrm{Na}^{+} \text {loss in } \\
\text { zebrafish larvae after acid challenge through } \mathrm{Gr}\end{array}$ & $\begin{array}{l}\text { Kumai et al. (2012) } \\
\text { Lin et al. (2011) } \\
\text { Cruz et al. (2013) } \\
\text { Lin et al. (2015) } \\
\text { Lin et al. (2016) } \\
\text { Kwong \& Perry (2013) }\end{array}$ & $\begin{array}{l}g r^{A T G} \mathrm{MOs} \\
g r^{\text {splic }} \mathrm{MOs} \\
m r^{A T G} \mathrm{MOs}\end{array}$ \\
\hline $\begin{array}{l}\text { Hypoxic response: } \\
\text { Gr is involved in hypoxic response }\end{array}$ & Vettori et al. (2017) & $g r^{A T G 1} \mathrm{MO}$ \\
\hline $\begin{array}{l}\text { Gr isoforms: } \\
\text { Gra regulates two specific clusters of genes according to } \\
\text { different concentration of cortisol } \\
\text { Grß is not involved in transcription regulation }\end{array}$ & $\begin{array}{l}\text { Chatzopoulou et al. (2015) } \\
\text { Chatzopoulou et al. (2017) }\end{array}$ & $\begin{array}{l}g r \alpha^{\text {splic }} \mathrm{MO} \\
\operatorname{gr} \beta^{\text {splic }} \mathrm{MO}\end{array}$ \\
\hline
\end{tabular}

Figure 2

Main citations and results on $\mathrm{gr}$ morpholino. 
First experiments with MOs were performed with $g r$ SPL-MO and revealed a negative role for GCs on zebrafish caudal fin regeneration after its amputation (Mathew et al. 2007). Later on, the same approach was used to identify compounds, including different synthetic GCs, able to modulate this process (Sengupta et al. 2012). More recently, further investigations demonstrated that a strong Gr-dependent upregulation of the oncofetal gene cripto-1 is possibly involved in the GC/Gr-mediated inhibition of regeneration (Garland et al. 2019).

Notably, the knockdown approach with $g r$ SPL-MO by Mathew et al. (2007) did not cause any overt developmental defect on embryos and larvae. This result was later confirmed by other papers and it is suggestive of a non-essential role of zygotic Gr during early zebrafish development (Pikulkaew et al. 2011).

Nonetheless, in teleosts, including zebrafish, $g r$ mRNA is the most abundant among the maternal transcripts of steroid hormones receptors (Pikulkaew et al. 2010), together with maternally derived cortisol (Alsop \& Vijayan 2008). The bioactivity of cortisol and the relevance of gr maternally supplied for normal development were demonstrated by the fact that ATG-MO knockdown of maternal transcripts produces multiple developmental defects including compromised embryonic and larval survival, morphological alterations, abnormal mesoderm formation with altered somitogenesis and gene expression (Pikulkaew et al. 2011, Nesan et al. 2012).

Moreover, transcriptomic analysis upon transient silencing of the receptor has been a powerful tool to potentially reveal direct and indirect interactors of the pathways involved in GC-Gr activity, as well as their relevance during embryogenesis. This approach allowed to identify $\mathrm{Gr}$ as a negative regulator of bone morphogenetic protein (BMP) signaling pathways, as demonstrated by downregulation of $b m p 2 a, b m p 2 b$ and $b m p 4$ (Nesan et al. 2012, Nesan \& Vijayan 2013). Additionally, according to the evidence that GCs can exert multiple functions, several other organs, including nervous system, heart and skeletal muscle, are also impacted during development (Nesan \& Vijayan 2013).

These results not only confirm the previously described zebrafish morphants phenotypes, but also reflect the effects observed in mice (Cole et al. 1995), suggesting extensively overlapping Gr functions in the two model species. Thus, maternal liposoluble hormones already present in the oocyte and $g r$ transcripts would represent a direct signaling link between the life experience of the mother and the capability of the progeny to cope with environmental and social challenges.
As maternal GC/GR signaling is found to be essential for normal development both in teleosts and mammals, the exposure to an excess of cortisol causes specific effects on offspring development, thus demonstrating, beyond any doubt, that these hormones are both correlated with maternal hormonal condition during oogenesis and biologically active throughout the first stages of embryogenesis (reviewed by Moisiadis \& Matthews 2014, Faught \& Vijayan 2018b). Therefore, GC concentration needs to be finely regulated, since excess has negative effects on fetal development (Busada \& Cidlowski 2017).

The approach of Wilson et al. (2016) to study the role of GC/Gr during development combined the $g r$ knockdown with enrichment of egg cortisol and hypoxia, in order to analyze their combined effects on development, behavior and growth (Wilson et al. 2016). These experiments confirmed the central role of $\mathrm{Gr}$ in development as $g r$ morphants showed impairments in hatch-rate, headtrunk angle and body length. Moreover, $g r$ morphants appeared to be less responsive to tactile stimuli as well as less motile when compared to control larvae. $g r$ morphants were raised to adulthood and showed significantly lower levels of cortisol when compared to controls, suggesting that $g r$ knockdown during development affects the physiology of adult fish (Wilson et al. 2016). In addition, these manipulations showed how the variations of GC activity during early development while affecting embryonic processes, are also risk factors for diseases in adults. For example, knocked-down embryos had severe defects in heart morphology and functionality and these modifications in cardiac structures were not recovered in adult life, suggesting a connection between GCs and heart dysfunctions (Wilson et al. 2015, 2016).

The $g r$ knockdown approach was adopted to study how hormones orchestrate acid-base balance and ion transport in fish, an issue recently reviewed by Guh \& Hwang (2017). Among the hormones involved in these physiological processes, cortisol has been demonstrated to regulate the differentiation process of epidermal ionocytes, cells that are localized in the gills and involved in ion homeostasis. As a consequence of Gr transient silencing, the number of these cells was reduced (Cruz et al. 2013), and the expression of several transporters, such as epithelial calcium channel (ECC) which normally controls $\mathrm{Ca}^{2+}$ uptake (Lin et al. 2011) and sodium-chloride cotransporter (NCC) required for the absorption of $\mathrm{Na}^{+}$ (Kumai et al. 2012, Kwong \& Perry 2013, Lin et al. 2016), were downregulated in $\mathrm{gr}$ morphants when compared to control larvae. Interestingly, knockdown experiments with splicing MOs for both $\mathrm{Gr}$ and $\mathrm{Mr}$ as well as 
pharmacological selective inhibition or activation of these receptors using RU-486 and aldosterone, respectively (Kumai et al. 2012), revealed that, in teleost fish, all these osmoregulatory functions, are carried out by the Gr and not by the Mr, as far as development is concerned (Lin et al. 2015). These results were later confirmed with the analysis of osmoregulation in a medaka mineralocorticoid receptor ( $m r)$ mutant (Sakamoto et al. 2016).

Chatzopoulou et al. used the MOs for the characterization of Gr transcriptional activity of the two different splicing variants, Gr $\alpha$ and Gr $\beta$. In particular, specific morpholinos hindering gra and gr $\beta$ mRNA formation were used, and the resultant morphant transcriptomes were compared. The work demonstrates that $\mathrm{Gr} \alpha$ regulates two partially overlapping gene clusters. Particularly, while a subset of Gro-regulated genes is expressed under basal conditions, the treatment with dexamethasone (DEX) elicits transcription of a second subset of genes, with very weak effect on the genes of the first cluster (Chatzopoulou et al. 2015). Moreover, a luciferase reporter assay suggests a dominantnegative effect of $\operatorname{Gr} \beta$ on Gr $\alpha$ transcriptional activity
(Chatzopoulou et al. 2015) but this is not confirmed in vivo, and thus the function of Gr $\beta$ isoform remains unclear (Chatzopoulou et al. 2017).

\section{In vivo visualization of GC/Gr transcriptional activity in zebrafish}

A modern approach for the visualization of signaling pathways activities in metazoans takes advantage from the generation of transgenic lines expressing reporter genes under the control of the DNA responsive elements bound by the specific transcription factor under investigation (Fig. 3). These experimental models have been developed also for the in vivo visualization of GC/Gr transcriptional activity starting from 2012 with the generation of the GRIZLY (glucocorticoid responsive in vivo zebrafish luciferase assay) by Weger et al. (2012). This assay is based on the transgenic zebrafish reporter line $T g$ (GRE:Luciferase) ${ }^{s b 6}$ or GRE-Luc, in which the expression of luciferase is driven by four concatemerized GREs. The specificity of this transgenic line was validated with both GC agonists

\begin{tabular}{|c|c|c|}
\hline \multicolumn{2}{|r|}{ Transgenic line generation } & $\begin{array}{c}\text { X-dpf larvae in } 96 \\
\text { wells plate } \\
\text { ble lines }\end{array}$ \\
\hline Results & Source & Transgenic line \\
\hline $\begin{array}{l}\text { GCs reporter based on luciferase } \\
\text { activity. } \\
\text { Applications: stress research, } \\
\text { environmental monitoring, and drug } \\
\text { discovery. }\end{array}$ & $\begin{array}{l}\text { Weger et al. (2012) } \\
\text { Weger et al. (2013) } \\
\text { Tsachaki et al. (2017) }\end{array}$ & $\operatorname{Tg}(\text { GRE:Luciferase })^{\text {sb6 }}$ \\
\hline $\begin{array}{l}\text { GCs reporter based on EGFP } \\
\text { fluorescence. } \\
\text { Applications: environmental or genetic } \\
\text { modulator of stress response signalling } \\
\text { and behaviour. }\end{array}$ & $\begin{array}{l}\text { Krug et al. (2014) } \\
\text { Brady et al. (2017) } \\
\text { Spulber et al. (2018) } \\
\text { Lee et al. (2018) } \\
\text { Hayward et al. (2019) } \\
\text { Nelson et al. (2019) }\end{array}$ & $\begin{array}{l}\text { Tg(6xGRE:EGFP, myl7:TagBFP })^{m n 48} \\
\text { d4EGFP }\end{array}$ \\
\hline $\begin{array}{l}\text { GCs reporter based on EGFP } \\
\text { fluorescence. } \\
\text { Applications: GC responsiveness to both } \\
\text { endogenous and exogenous stimuli; } \\
\text { high spatial resolution. }\end{array}$ & $\begin{array}{l}\text { Benato et al. (2014) } \\
\text { Sallin \& Jaźwińska (2016) } \\
\text { Facchinello et al. (2017) } \\
\text { Vettori et al. (2017) } \\
\text { Morbiato et al. (2017) } \\
\text { Schaeffer et al. (2019) }\end{array}$ & $\operatorname{Tg}(9 x G C R E-H S V . U 123: E G F P)^{i a 20}$ \\
\hline
\end{tabular}

Figure 3

Main citations on GC-responsive transgenic lines. 
and antagonists, and analyzed for the dose-dependence of luciferase activity. Notably, GRIZLY reports the increase of cortisol concentration in larvae upon exposure to osmotic stress thus demonstrating that this transgenic line allows to monitor stress-dependent cortisol production. This response was found to be detectable in 4-dpf (days post fertilization) transgenic larvae and significant at 5-dpf, thus confirming previous reports of Alsop \& Vijayan (2008) regarding the ontogenesis of zebrafish stress response. The easy quantification of the luciferase activity makes this line a useful model for in vivo highthroughput screening of new GC agonist or antagonist drugs (Weger et al. 2013), or analysis of environmental toxins as demonstrated by the responsiveness of GRE:Luc line to tributyltin (TBT), a pollutant that is metabolically converted to the Gr antagonist dibutyltin (DBT) in the liver (Ohhira et al. 2003). As a matter of fact, while both TBT and DBT treatments inhibit luciferase activity in the GRE:Luc zebrafish line, only DBT is able to do it in AB.9 GRE:Luc cells, due to the lack of the specific metabolic process catalyzing its synthesis in this cellular model (Weger et al. 2012).

In 2014 Krug et al. generated the Tg(6xGRE:EGFP,myl7 :TagBFP)mn48 transgenic line, called SR4G, a reporter model characterized by six composite GRE sequences upstream of the coding sequence of EGFP (enhanced green fluorescent protein). This reporter line was validated not only assessing the response to osmotic stress or treatment with GC agonists or antagonists, but also with fluorescence analysis of transgenic mosaic larvae TALENs engineered to target exon 2 of the $n r 3 c 1$ gene. As expected, the $g r$ KO prevented the EGFP mRNA increase stimulated by a GC treatment. Furthermore, fluorescence levels increased after treatment with nicotine, used as an alternative activator of the HPI axis. Finally, EGFP mRNA levels mirror the oscillations of basal cortisol concentrations with the circadian rhythm (Krug et al. 2014).

Almost simultaneously, Benato et al. generated the Tg(9GCRE-HSV.Ul23:EGFP)iazo transgenic zebrafish line, from herein named ia20. The reporter plasmid inserted in the genome of this line contains nine GRE consensus sequences followed by the EGFP coding sequence. This reporter is different from the GRE:Luc both in the number of GRE repeats (which potentially can affect sensitivity) and in the spatial resolution of the signal when embryos/ larvae, but also adult tissues, are analyzed in confocal microscopy. The high sensitivity of this transgenic line, confirmed by expression analysis of EGFP and $f k b p 5$ as a $\mathrm{GC}$ target gene, allows to visualize the response not only to exogenous but also to endogenous GCs and to identify tissues/structures that are responsive to these hormones with very high spatial resolution. Similarly to the SR4G reporter line, the EGFP activity of ia20 fish decreases with Gr knockdown and RU-486 treatment and shows variations in tissues specificity and intensity with respect to the light cycle (Benato et al. 2014).

After publication, all these reporter lines have found more applications in research: the GRIZLY assay was used to document the absence of 11ß-hydroxysteroid dehydrogenase type 1 activity in zebrafish (Tsachaki et al. 2017) and for in vivo detection of drugs able to interfere with the GC system.

The SR4G reporter demonstrated that handling zebrafish larvae during the execution of the intestinal transit assay induces an increase in cortisol secretion (Brady et al. 2017) and in vivo confirmed the interaction between methylmercury, an environmental contaminant, and the Gr, previously suggested by molecular dynamics simulations. Moreover, this interaction was found to have a role in the developmental neurotoxic effects determined by this molecule (Spulber et al. 2018). In addition, this line was adopted to monitor GC activity and confirm the loss of HPI functionality in the $m c 2 r$ (adrenocorticotropic hormone receptor) homozygous mutant fish (Lee et al. 2019).

Other applications of this reporter line were the visualization of (1) the hazard in the co-administration of aminoglycoside antibiotics with GCs as the latter can both increase the sensitivity of the lateral line to aminoglycoside damage (Hayward et al. 2019), (2) how GC/Gr complex blocks the functional recovery after spinal cord injury (Nelson et al. 2019).

The transgenic line ia20 was similarly used to monitor GC activity in the first CRISPR/Cas9 zebrafish mutant line developed for Gr (Facchinello et al. 2017, Morbiato et al. 2019), to study the cross-talk between GC/Gr and the hypoxic transcriptional responses (Vettori et al. 2017), to demonstrate how an increase of cortisol induced by stress impairs the regenerative potential of zebrafish heart (Sallin \& Jaźwińska 2016) and to visualize the renin effects on pronephros development, as this line shows a robust expression of EGFP in fish kidney (Schaeffer et al. 2019).

\section{Mutants of glucocorticoid receptors in zebrafish}

The MO-induced knockdown of gr translation was a valuable tool to overcome the unavailability of targeted https://joe.bioscientifica.com

https://doi.org/10.1530/JOE-20-0173 (c) 2020 Society for Endocrinology Published by Bioscientifica Ltd. Printed in Great Britain 
mutagenesis techniques in $D$. rerio to study the $\mathrm{Gr}$ response in a living model organism. On the other hand, a knockdown strategy can have problems due to (1) offtarget effects when the MO recognizes and works on genes other than those under consideration; (2) the lack of high precision and reproducibility in the amount of injected oligomers as well as (3) the problem of suitable experimental controls. Moreover, although this technique can help to elucidate the effects of a developmental transient knockdown on adult physiology (Wilson et al. 2015), it does not allow to analyze the biological effects due to the absence of $g r$ in post-larval life.

Before the development of targeted $\mathrm{KO}$ techniques, the only available approaches to obtain zebrafish mutants was to perform laborious and time-consuming forward genetics assays. In 2005, a screen for zebrafish mutants of the vertebrate sensory system based on behavioral analyses, in this case on the visual background adaptation (VBA) assay, enabled the identification of a $g r$ mutant line called s357 (Muto et al. 2005). The VBA assay is based on the neuroendocrine response determining the shrinkage of zebrafish melanocytes when larvae are exposed to bright background (Kurrasch et al. 2009). Nowadays, this test is used in strains defective in the synthesis of GCs for the preliminary selection of homozygous recessive larvae, in which this response is lost (Griffiths et al. 2012, Muto et al. 2013, Griffin et al. 2016, Eachus et al. 2017, Facchinello et al. 2017, Weger et al. 2018, Lee et al. 2019, Gans et al. 2020, Li et al. 2020, Marchi et al. 2020).

The $g^{5357 / 3357 m u t a n t}$ is characterized by a point mutation in the DBD that leads to a substitution of an arginine with a cysteine at the position 443 . Hence, this mutant $g r$ gene codes for a protein that is able to bind GCs and to translocate to the nucleus but cannot efficiently bind to GREs (Griffiths et al. 2012).

Given their overall morphological and physiological similarities compared to WT fish, grs357/s357mutants present higher chronic levels of cortisol both at larval and adult stages (Griffiths et al. 2012, Ziv et al. 2013). Furthermore, transcript levels of corticotropin-releasing hormone ( $\mathrm{crh}$ ) and proopiomelanocortin A (pomca), measured with qRT-PCR and in situ hybridization, are significantly higher in mutants when compared to WT siblings. All these data confirm the loss of HPI negative feedback loop, activated in WT fish by Gr- and GRE-mediated transcriptional regulation. Therefore, the $g^{5357 / 3357}$ zebrafish line was employed as a model to study HPI hyperactivation and development of depression, a condition that is also associated with GCs in humans; it is due to functional (GC resistance) or expressional changes in the $\mathrm{Gr}$
(Baumeister et al. 2016). With respect to both WT larvae and adults, mutants respond with a reduced exploratory behavior and impaired habituation to stressful conditions, like new tanks, and startle response (Ziv et al. 2013). grs357/s357larvae show also a lower spontaneous activity (Griffiths et al. 2012). Interestingly, the anxiolytic drug diazepam and the antidepressant molecule fluoxetine, a selective serotonin reuptake inhibitor, are able to reduce the depression-like mutant behavior, possibly through modulation of HPI axis hyperactivity (Ziv et al. 2013). On the other hand, DEX treatment cannot induce a repression of the stress markers in mutant fish, a fact consistent with the abrogation of the negative feedback loop in gr $^{s 357 / s 357}$.

These results point out the evolutionary conservation of the neuroendocrine circuits of stress among Vertebrates while suggesting the huge potential of zebrafish $g r$ mutant lines for the screening of new pharmacological molecules for anti-depression and affective disorders therapies.

In addition, Muto et al. (2013) found that light adaptation is disturbed in the retina of $\mathrm{gr}^{5357 / 3357 \text { larvae as }}$ they display behavioral delays when suddenly re-exposed to light after a dark period, as well as some changes in gene expression in the dopaminergic signaling axis, a key neuromodulator of the retinal network (Muto et al.

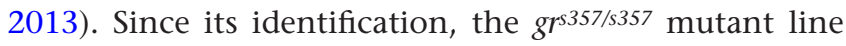
has been used by several research groups to analyze the regulation of sleep/wake states by different neuropeptides like neuromedin U (Chiu et al. 2016) or prokinecitin 2 (Chen et al. 2017) or the neuroendocrine mechanisms involved in the perception of food (Filosa et al. 2016). Other applications of this line are listed in Fig. 4, which covers a considerable number of different physiological processes and underlies the value of the zebrafish model (Kwan et al. 2016, Brun et al. 2019, Mosser et al. 2019, Palstra et al. 2019, Sireeni et al. 2020).

The design of CRISPR/Cas9 targeted mutagenesis protocols and their application, with the subsequent possibility to make reverse genetics studies in zebrafish, was a breakthrough in the development of mutants (Hwang et al. 2013). This technique allowed Facchinello et al.

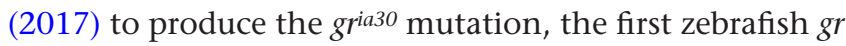
null allele. Since then, many zebrafish mutant lines have been generated targeting different positions of the protein as summarized in Fig. 5.

The gria30 contains a 5-nucleotide insertion in the second exon of the gene, which results in a frameshift mutation leading to the generation of a premature stop codon. The gria30/ia30 mutants are viable and fertile, although their offspring showed a reduced survival rate when compared to both grs $^{5357 / 3357}$ and WT. 


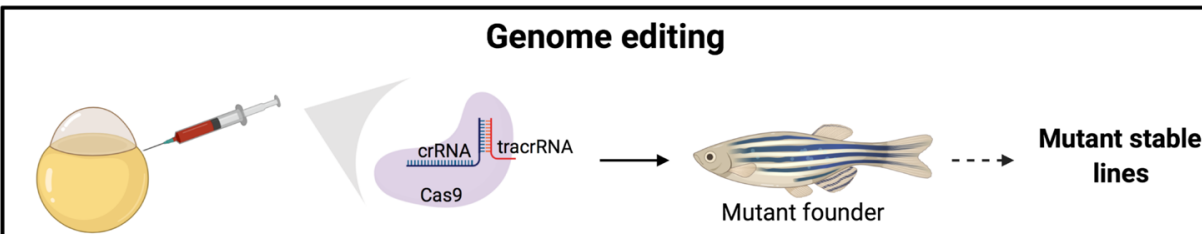

one-cell embryo

\begin{tabular}{|c|c|c|}
\hline Results & Source & Allele \\
\hline $\begin{array}{l}\text { HPI axis, stress response and behaviour: } \\
\text { Gr KO results in chronically high cortisol concentration } \\
\text { Gr is essential for the correct response to stress } \\
\text { The absence of a functional Gr leads to a depression-like } \\
\text { behaviour that can be rescued by fluoxetine. } \\
\text { The anxiogenic and depression-like behaviour due to loss } \\
\text { of Gr signalling develops after the larval stages. } \\
\text { Gr and Mr are both required to control HPI axis activity } \\
\text { and work through different mechanisms. } \\
\text { Gr, but not Mr, is involved in correct responses to } \\
\text { different stressors like light stimuli and salinity } \\
\text { Mutants for Cyp21a2, Cyp11a2, Fdx1b show a GCs } \\
\text { deficient phenotype and can be used as a model for } \\
\text { glucocorticoid-deficiency }\end{array}$ & $\begin{array}{l}\text { Griffiths et al. (2012) } \\
\text { Facchinello et al. (2017) } \\
\text { Faught \& Vijayan (2018a) } \\
\text { Ziv et al. (2013) } \\
\text { Sireeni et al. (2020) }\end{array}$ & $\begin{array}{l}g r^{5357} \\
g r^{j a 30} \\
g r^{c a 401} \\
m r^{c a 402} \\
g r^{m n 61} \\
g r^{m n 62} \\
g r^{m n 63} \\
g r^{m n 64} \\
g r^{m n 65} \\
m r^{m n 66} \\
m r^{m n 67} \\
\\
c y p 21 a 2^{\text {uob2122 }} \\
c y p 21 a 2^{\text {uob2123 }} \\
f d x 1 b^{\text {uob205 }} \\
\text { cyp11a } 2^{-/}\end{array}$ \\
\hline $\begin{array}{l}\text { Hypoxia response: } \\
\text { GCs determine pseudohypoxia through DNA-binding } \\
\text { independent mechanisms } \\
\text { Hypoxia regulates steroidogenesis, but Gr transcriptional } \\
\text { activity is dampened when Hif1 activity is induced } \\
\text { Gr and Mr are both directly involved in hypoxic response }\end{array}$ & $\begin{array}{l}\text { Vettori et al. (2017) } \\
\text { Marchi et al. (2019) }\end{array}$ & $\begin{array}{l}g r^{j a 30} \\
g r^{\text {sh543 }}\end{array}$ \\
\hline $\begin{array}{l}\text { Neurobiology and circadian rhythm: } \\
\text { Gr is essential for regulation of retinal light adaptation } \\
\text { Regulation of sleep/wake states by Neuromedin } \mathrm{U} \text { and } \\
\text { Prokineticin } 2 \text { do not require } \mathrm{Gr} \text {. } \\
\text { GCs regulate the amplitude of the circadian rhythm and is } \\
\text { involved in the feeding state of zebrafish larvae } \\
\text { GC/Gr is essential for feeding synchronization of circadian } \\
\text { clock }\end{array}$ & $\begin{array}{l}\text { Muto et al. (2013) } \\
\text { Chiu et al. (2016) } \\
\text { Chen et al. (2017) } \\
\text { Mosser et al. (2019) } \\
\text { Filosa et al. (2017) } \\
\text { Morbiato et al. (2019) }\end{array}$ & $\begin{array}{l}g r^{5357} \\
g r^{j a 30}\end{array}$ \\
\hline $\begin{array}{l}\text { Muscle and bone development: } \\
\text { GCs affect the white skeletal muscle transcriptome but not } \\
\text { the exercise-enhanced growth } \\
\text { Gr is fundamental for bone and cartilage correct } \\
\text { formation. }\end{array}$ & $\begin{array}{l}\text { Palstra et al. (2019) } \\
\text { Jiang et al. (2020) }\end{array}$ & $\begin{array}{l}g r^{5357} \\
g r^{-/-}\end{array}$ \\
\hline $\begin{array}{l}\text { Growth and metabolism: } \\
\text { Gr controls larval growth and muscle glucose uptake } \\
\text { Both Gr and Mr are involved in GCs-dependent lipid } \\
\text { regulation during post-natal growth. } \\
\text { Larval transcriptome shows that Mr regulates lipid } \\
\text { synthesis and Gr activation promotes lipid catabolism } \\
\text { Excess of cortisol suppresses growth } \\
\text { Loss of Fdx1b blocks GCs' synthesis, that leads to } \\
\text { dysregulation of many metabolic pathways, including } \\
\text { reprogramming of glutamine metabolism }\end{array}$ & $\begin{array}{l}\text { Faught \& Vijayan (2019a) } \\
\text { Faught \& Vijayan }(2019 b) \\
\text { Faught \& Vijayan (2020) } \\
\text { Weger et al. (2018) }\end{array}$ & $f d x 1 b^{u o b 205}$ \\
\hline
\end{tabular}

Figure 4

Main citations and results on zebrafish mutant lines. 
Figure 4 Continued.

\begin{tabular}{|c|c|c|}
\hline $\begin{array}{l}\text { Inflammation: } \\
\text { GCs reduce neutrophil migration towards wound site and } \\
\text { the inflammatory response } \\
\text { Gr is essential for correct response to inflammation } \\
\text { Some functions of Gr in inflammatory response appear to } \\
\text { be DNA-binding independent } \\
\text { klf9 is a Gr target gene and encodes for a transcription } \\
\text { factor that is involved in the expression of inflammatory } \\
\text { genes } \\
\text { Gr signalling is involved on embryonic hematopoietic } \\
\text { stem and progenitor cell regulation }\end{array}$ & $\begin{array}{l}\text { Chatzopoulou et al. (2016) } \\
\text { Facchinello et al. (2017) } \\
\text { Gans et al. (2020) } \\
\text { Kwan et al. (2016) }\end{array}$ & $\begin{array}{l}g r^{5357} \\
g r^{j a 30} \\
g r^{369} \\
g r^{5357}\end{array}$ \\
\hline $\begin{array}{l}\text { Toxicity: } \\
\text { Developmental neurotoxicity of methylmercury is due to } \\
\text { interference with Gr } \\
\text { GCs sensitizes the hair cell of the lateral line to } \\
\text { aminoglycoside toxicity } \\
\text { Gr activation is involved in polystyrene nanoplastics } \\
\text { adverse effects }\end{array}$ & $\begin{array}{l}\text { Spulber et al. (2018) } \\
\text { Hayward et al. (2019) } \\
\text { Brun et al. (2019) }\end{array}$ & $g r^{5357}$ \\
\hline
\end{tabular}

To analyze GC signaling in vivo, the gria30/ia30 $\mathrm{KO}$ line was compared with the gr $^{5357 / 3357}$ in Tg(9GCRE-HSV.Ul23:EGFP) ia20 transgenic background. Larvae of the two mutant lines show both a significant reduction in fluorescence and insensitivity to exogenous GC-based treatment, when compared to WT siblings, thus confirming the lack of the DNA-binding-dependent transcriptional activity. These data were also confirmed by qRT-PCR analysis of $f k b p 5$, a GC target gene, whose expression is significantly reduced in both mutants and upregulated by DEX only in WT sibling larvae. As expected, also the gria30/ia30 null mutant line is characterized by high levels of whole-body cortisol, associated with overstimulated basal levels of $\mathrm{crh}$ and pomca transcripts and HPI axis unresponsiveness to a mechanical stressor (Facchinello et al. 2017).

Remarkably, analyses after inflammatory stimuli suggest that gr $^{5357 / 3357}$ mutants differ from gria30/ia30, possibly due to DNA-binding-independent activities of Gr, such as tethering with other transcription factors, preserved only in gr $^{3537 / s 357}$. In particular, inflammationrelated gene expression is stimulated in WT after dextran sulfate sodium (DSS) treatment, while the following DEX treatment can restore it to basal levels. In gria3o/ia30 mutants, the expression of markers of inflammation does not change after DSS and DEX treatment, suggesting that the absence of $\mathrm{Gr}$ determines the inability to properly respond to inflammation. Notably, inflammationrelated genes appeared to be upregulated by DSS in gr ${ }^{5357 / 3357}$ larvae when compared to untreated ones, even if their upregulation is lower than in treated WT larvae. Furthermore, DEX is able to restore basal conditions in gr $^{5357 / 3357}$ revealing that this mutant line is able to respond to exogenous GCs, while griazo/ia30 is not (Facchinello et al. 2017). Although the inflammatory issue in gria30/ia30 needs to be analyzed more in details, the results obtained are consistent with the findings that the GC trans-repression of inflammatory responses, carried out by GR proteinprotein interactions, is the preeminent mechanism used
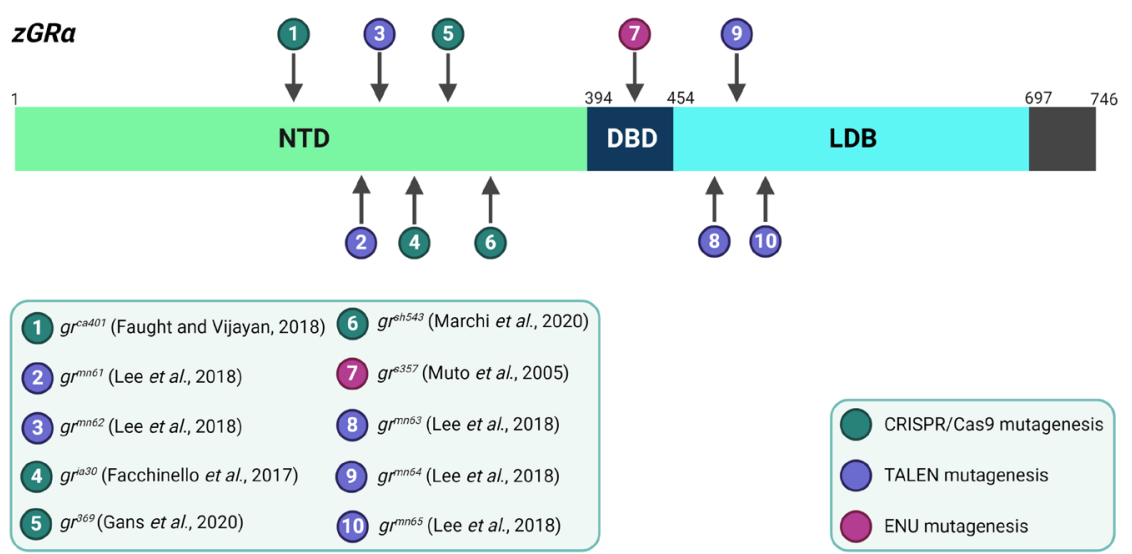

CRISPR/Cas9 mutagenesis

TALEN mutagenesis

ENU mutagenesis

\section{Figure 5}

Schematic representation of zebrafish glucocorticoid receptor organization. The figure highlights the position of the mutations in the $\mathrm{gr}$ mutant lines described in this paper and the experimental approach used to generate them. https://joe.bioscientifica.com https://doi.org/10.1530/JOE-20-0173 (c) 2020 Society for Endocrinology Published by Bioscientifica Ltd. Printed in Great Britain 
to downregulate the activity of many transcription factors involved in the immune response such as AP-1 or NF- $\mathrm{KB}$ (reviewed in Ratman et al. 2013). The maintenance of Gr tethering activities in $\mathrm{gr}^{5357 / 3357}$ is furthermore confirmed by the analysis of the crosstalk between GCs and hypoxic transcriptional responses: hypoxia-inducible factor (Hif) activation by GC-based treatment is still expressed in the mutant line with a missense mutation in its DNA binding domain ( $\mathrm{gr}^{\mathrm{s} 357 / 3357)}$ but it is absent in the KO one (Vettori et al. 2017), a result further confirmed later on by Marchi et al. with the generation of another $\mathrm{gr}$ mutant line ( $\left.\mathrm{gr}^{\mathrm{sh} h 43}\right)$ (Marchi et al. 2020).

In 2019, Morbiato et al. used the gria30/ia30 line to study circadian clock entrainment. Like the majority of living organisms, zebrafish have adapted their physiology to anticipate the changes of environmental conditions rhythmically occurring during the day. The molecular mechanisms underlying this adaptation are generally defined as 'circadian clock'. In vertebrates, rhythmicity is given by multiple oscillatory networks that are orchestrated by a central oscillator, tuned by environmental synchronizers (zeitgebers) such as light:darkness cycle, temperature cycles and food availability. Whereas behavioral activity and clock gene expression are entrained by the light:darkness (LD) cycle, feeding entrainment is severely dampened in gria30/ia30 mutants, both in adults and in larvae, thus confirming the role of GC-mediated Gr signaling in this environmental synchronizer in a non-mammalian species. Moreover, mutants also show a significant reduction of period 2 (per2) expression, a crucial component of the circadian clock in fish. Additionally, expression of phosphoenolpyruvate carboxykinase 2 (pck2) and sterol regulatory elementbinding protein 1 (srebp1) genes, which are involved in glucose and lipid metabolism, is altered in gria30/ia30 mutants when compared to WT. While the rhythmicity of pck2 is completely abolished, srebp 1 rhythm undergoes a phase shift, anticipating the acrophase of its expression. The study confirms that, like in mammals (Challet 2019), in non-mammalian vertebrates GC/Gr may function as an endocrine signal able to regulate feeding synchronization with circadian clocks (Morbiato et al. 2019).

To distinguish the different physiological roles of $\mathrm{Gr}$ and $\mathrm{Mr}$ in the zebrafish model, Faught \& Vijayan (2018a) produced and compared $g r$ (grca401/ca401) and $m r$ (mra402/ca402) mutant lines. Although the transcript levels of $g r$ and $m r$ in the corresponding mutant lines are not reduced with respect to WT, as normally happens for the activation of the nonsense-mediated mRNA decay (NMD) machinery (Chang et al. 2007), the loss of proteins is confirmed by Western blotting. Furthermore, grca401/ca401 mutants show the physiological features due to the $\mathrm{Gr}$ silencing, such as high level of cortisol and deregulation of the HPI axis. On the contrary, in the $m r$ mutant line cortisol basal level is normal. Comparative analysis of these mutant lines demonstrates that both $\mathrm{Gr}$ and $\mathrm{Mr}$ are involved in the regulation of stress axis activation but with different functions: while grca401/ca401 mutants are unable to produce a stress response, in mrca402/ca402 the reaction to acute stress is delayed. Notably, because the loss of $\mathrm{Mr}$ results in behavioral changes which are not rescued by the administration of exogenous GCs, both Gr and $\mathrm{Mr}$ are required and have complementary activities in stressrelated behavior (Faught \& Vijayan 2018a). This response, mediated by MR and GR, also occurs in mammals, besides the osmoregulatory process (Joëls \& de Kloet 2017).

Since GC/Gr signaling exerts a significant role for energy and metabolic homeostasis in muscle, Faught \& Vijayan (2019a) analyzed the outcomes of Gr KO in the grca401/ca401 mutant line on muscle physiology. In agreement with muscle-specific $G R$ mutant mouse models (reviewed by Whirledge \& DeFranco 2018), also these hypercortisolemic zebrafish $g r$ mutants have higher body mass due to an increase of lipid and protein, but not of carbohydrate, content. Moreover, while the glucose level increases in stressed WT fish, this response is hampered in mutants that show also a higher permeability to glucose in muscle but not in liver. This observation matches with the higher activity in mutants of hexokinase, a crucial enzyme in glucose muscular uptake and utilization. Accordingly, loss of body weight during fasting was reduced in mutants. Thus, GC/Gr was identified as a growth suppressor in fish, potentially acting on protein catabolism (Faught \& Vijayan 2019a). These results were later confirmed with the analysis of corticosteroid receptors (CRs) specific functions during zebrafish larval growth (Faught \& Vijayan 2020). According to these authors, both $\mathrm{Gr}$ and $\mathrm{Mr}$ are involved in postnatal growth regulation. Growth suppression due to GC excess results from Gr mediated upregulation of muscle proteolytic markers like muscle RING-finger protein 1 (murf1) and regulated in development and DNA damage responses 1 (redd1), although the activation of $\mathrm{Mr}$ is also required for this catabolic effect. While stimulation of protein synthesis, important for postnatal growth, is promoted by $\mathrm{Mr}$, Gr seems to play its catabolic functions when GCs increase (Faught \& Vijayan 2020).

A similar comparative experimental setting was conceived by Faught \& Vijayan (2019b) to study the roles of $\mathrm{Gr}$ and $\mathrm{Mr}$, as well as their specific interaction, 
on lipid metabolism, under basal and stressful conditions (cortisol treatment). In their work, the authors showed that $\mathrm{Mr}$, the only receptor present in Gr mutants, plays a fundamental role in the biosynthesis of triglycerides and in lipid accumulation by downregulating the transcription of the enzyme lipoprotein lipase, thus explaining the increase of adipose tissue previously reported in $\mathrm{Gr}$ mutant lines (Facchinello et al. 2017, Faught \& Vijayan 2019a). Moreover, similarly to what happens in muscle, transcriptome analysis of mutant larvae demonstrates how $\mathrm{Mr}$ and $\mathrm{Gr}$ control the transcription of different and specific genes, with $\mathrm{Mr}$ more involved in lipid synthesis while Gr in lipid catabolism (Faught \& Vijayan 2019a).

Lee et al. analyzed the correlation between rapid locomotor responses following different acute stressors and the activity of the HPI axis (Lee et al. 2019). These behavioral responses are different depending on the stressor and are abolished in zebrafish mutant lines that lack ACTH receptor $(m c 2 r)$, which is crucial for the synthesis of GCs. The authors conclude that an intact HPI axis is required for a rapid locomotor response. Moreover, analysis of new $g r$ and $m r$ mutant lines, together with the use of specific antagonists suggest that Gr and not $\mathrm{Mr}$ is the receptor involved in these responses (Lee et al. 2019). This result contrasts with the Faught \& Vijayan (2018a) hypothesis of a complementary role of Mr and Gr receptors in stress response. Indeed, the authors conclude that further analyses are required to better clarify the role of $\mathrm{Mr}$ in stress and rapid locomotor response (Lee et al. 2019).

Recently, Gans et al. (2020), analyzed the transcriptomes of WT and $g r$ mutants $\left(g r^{369 / 369}\right)$ upon chronic cortisol treatment. The outcome of a transcriptional activity in WT larvae similar to that of $\mathrm{gr}^{369 / 369}$ when chronically treated with cortisol, is explained by the authors with the development of Gr resistance. Moreover, they identified the transcription factor Kruppel-like factor 9 (Klf9), for which they generated a mutant line, as a crucial player in the regulation of the transcriptional response to GCs (Gans et al. 2020).

Finally, Jiang et al. (2020) generated a gr mutant line to study bone mineralization and the transcriptional control of genes involved in this process, as well as to clarify the role of $\mathrm{GC} / \mathrm{Gr}$ in the establishment of osteoporosis and predisposition to bone fracture, one of the major side effects of chronic therapeutic treatment with GCs. Analysis of their mutant line shows that $g r \mathrm{KO}$ negatively affects the cartilage development, reduces the bone mineralization area, and modify the expression of bone-related genes, such as alkaline phosphatase (alp)

(c) 2020 Society for Endocrinology Published by Bioscientifica Ltd. Printed in Great Britain and acid phosphatase 5a (acp5a). Differently from other papers that report how GCs downregulated the expression of matrix metalloproteinases ( $m m p 9$ and mmp13) after their upregulation during the inflammatory response (Tuckermann et al. 1999, Eberhardt et al. 2002, Chatzopoulou et al. 2016, Facchinello et al. 2017), these authors found an upregulation of $m m p$ genes by treatment with prednisolone, a synthetic GC. Although these differences could be due to the GCs used, their concentration, length of treatment as well as developmental stage, an in-deep analysis of transcriptional control of these proteins by GCs could help to better elucidate the role of GCs in the transcriptional regulation of $m m p$ genes.

To our knowledge, only three null mutant lines for corticosteroid receptors were developed so far in teleost models other than zebrafish, two in medaka and one in tilapia. The first medaka mutant line was generated for Mr. This receptor is prevalently expressed in brain and eyes, and analysis of the mutant line rules out the involvement of $\mathrm{Mr}$ in body fluid regulation, confirming results previously obtained by using morpholinos (Sakamoto et al. 2016). Since $m r$ mutants show abnormal responses to visual stimuli, the authors suggest a major role for $\mathrm{Mr}$ on behavior (Sakamoto et al. 2016), in agreement with zebrafish $m r$ mutant results (Faught \& Vijayan 2018a).

The second medaka mutant line was employed to study the role of $\mathrm{Gr}$ in osteoblast and osteoclast function by $\mathrm{KO}$ of the paralogue gene $g r 2$, since this was considered more responsive to GCs (Azetsu et al. 2019). Exploiting a transgenic background for osteoclasts and osteoblasts visualization and the gr2 mutation, these authors show that the delay of fracture healing that follows chronic GC treatment is due to the suppression of osteoclast recruitment and accumulation of osteoblasts at the healing site (Azetsu et al. 2019).

Although the results obtained with $g r$ and $m r$ knock down and the $m r$ medaka mutant line converge toward a clear role of Gr on acid-base balance and ion transport, to our knowledge, this evidence has not been confirmed with specific experiments or expression analyses performed on the different $g r$ mutant lines available. However, despite the lack of this crucial regulation, $g r$ mutants are viable. This suggests the activation of compensatory mechanisms based on complementary pathways or the upregulation of paralogue or related genes whose products can compensate for the loss of Gr. As a matter of fact, Gr and Mr proteins are closely related and derive from the gene duplication process of an ancestral corticoid receptor (CR) (Baker \& Katsu 2017). 
To compensate for the loss of $m r$, medaka $m r \mathrm{KO}$ results in an increase of gr1 expression (one of the two paralogue $g r$ genes present in this teleost species) in brain and eyes but not in the osmoregulatory organs (Sakamoto et al. 2017), confirming the lack of Mr activities in ion balance physiology. In zebrafish, compensation between CRs can be detected in the gria30 mutant line that shows a four-times increase of $m r$ expression in 5-dpf larvae. On the other side, an even more intense increase of $g r$ transcripts was measured in the $m$ ria32 mutant line (A Dinarello \& L Dalla Valle, unpublished observations).

Another key point of $\mathrm{Gr}$ function is related to reproduction, since GCs have been proposed to play a crucial role in this process both in mammals (Whirledge \& Cidlowski 2017) and in fish (Faught \& Vijayan 2018b). Zebrafish $g r$ homozygous mutants are genetically viable, but their fertility is significantly reduced, in particular with aging (Facchinello et al. 2017), a result confirmed also by Gans et al. (2020). As hypothesised by Faught \& Vijayan (2018b), our analysis on gria30/ia30 females confirms that GCs and Gr control ovarian maturation and the ovulation process. In addition, we found that the complex is also deeply involved in macromolecular composition and quality of the oocyte cytoplasm (F Maradonna, G Gioacchini, V Notarstefano, CM Fontana, F Citton, L Dalla Valle, E Giorgini \& O Carnevali, unpublished observations).

The study of GC function can also be addressed by blocking their synthesis through interference at different steps of steroidogenesis, the highly articulated and complex metabolic pathway supported by the enzymes involved in the biosynthesis of steroid hormones. Steroidogenesis takes place in the classical steroidogenic organs like gonads, adrenals and placenta, as well as in many peripheral tissues. Although some of these bioactive steroids can be produced de novo in small amounts, local steroids usually derive from the metabolism of circulating inactive precursors (Miller 2017).

The steroidogenic enzymes can be divided into two major classes: the first constituted by hydroxysteroid dehydrogenases (HSDs) and the second constituted by cytochrome P450, the latter in turn divided into type I, mitochondria integral proteins, and type II, targeted to the endoplasmic reticulum (Miller 2017). In particular, cortisol synthesis from cholesterol requires the activity of three P450 steroid hydrolases, as reported in Fig. 6, where the enzymes involved in GC synthesis, and already targeted in zebrafish with genetic $\mathrm{KO}$, are underlined.
In addition, all P450 enzymes (also called CYP) require reducing equivalents to catalyze their reactions, hence, steroid synthesis depends on their availability. Electrons for mitochondrial P450 enzymes, (type I enzymes, Cyp11a1, Cyp11a2 and Cyp11c1 in zebrafish) are provided by NADPH through two electron transfer proteins - ferredoxin reductase and ferredoxin - whereas P450 type II enzymes depend on the electron donor enzyme cytochrome P450 oxidoreductase (POR) (Miller et al. 2017).

Zebrafish has two ferredoxin paralogs, Fdx1 and Fdx1b. Silencing of the paralog $f d x 1 b$ gene, mainly expressed in steroidogenic tissues, was performed by

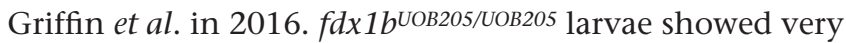
limited GC synthesis and the typical physiological features due to impairment of GC signaling, already described for gr mutant lines. Knockdown of the other paralog gene, $f d x 1$, severely impairs early zebrafish development, thus preventing the analysis of its effects on the steroidogenic pathway (Griffin et al. 2016). Subsequent analysis by Weger et al. (2018) of the $f d x 1 b$ cortisol-deficient zebrafish line focused both on metabolic changes and on the expression of genes involved in metabolic pathways. Results were then compared with those obtained both from a zebrafish model of secondary adrenal insufficiency, the chokh/rx3 strong mutant fish line that presents corticotrope cells deficiency associated with reduced cortisol levels (Dickmeis et al. 2007), and from human patients affected by primary insufficiency. Among the effects found in $f d x 1 b$ mutants, hence regulated by GCs, there are: a reduced transcription of liver and intestine glutaminases ( $g l s 2 a$ and $g s l 2 b$ ), resulting in the increase of glutamine levels, reduction of antioxidant glutathione synthesis and consequent increase of oxidative stress markers, and post-transcriptional regulation of purine synthesis enzymes. Based on these results, the $f d x 1 b$ mutant line has been proposed as an animal model for the study of human pathologies linked to GC deficiency, and also for the identification of biomarkers for the improvement of adrenal insufficiency diagnosis.

Adult $f d x 1 b$ mutant males show defects linked to sexual determination and reproduction such as feminization of secondary sexual characteristics, disorganization of testis morphology, impairment of sperm, breeding behavior, and infertility. Androgen production decreases, further confirming that Fdx1b is required for the activity of the $11 \beta$-hydroxylase, the enzyme encoded by the cyp11c1 gene (Oakes et al. 2019). This enzyme catalyzes the conversion of 11-deoxycortisol into cortisol but also 


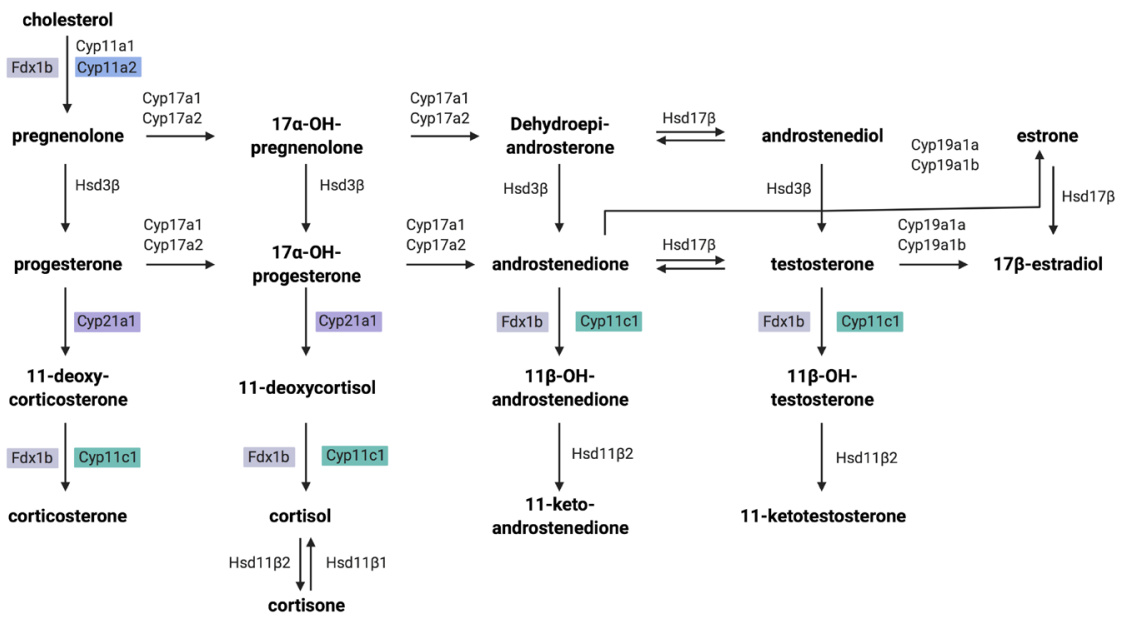

\section{Figure 6}

Schematic representation of the steroidogenic pathway. The biosynthetic pathway is not complete but focused on the enzymes required for GC synthesis. Colored boxes highlight the mutated proteins. converts testosterone and androstenedione to $11 \beta-\mathrm{OH}-$ testosterone and $11 \beta-\mathrm{OH}$-androstenedione, two precursors of 11-ketotestosterone, the hormone that binds the androgen receptor (Tokarz et al. 2015) (Fig. 6).

The steroidogenic pathway for GC synthesis has been blocked also by KO of the cyp21a2 gene that encodes the 21-hydroxylase enzyme, essential for the synthesis of GC hormones (Eachus et al. 2017). This block determines not only cortisol deficiency but also the accumulation of cortisol precursor like 17-hydroxyprogesterone and 21-deoxycortisol. Unfortunately, the outcomes of this effect have not been analyzed.

The cyp11a2 zebrafish mutant line generated by Li et al. (2020) presents GC deficiency and all-male fish showing a moderately feminized phenotype. While cyp11a1 is present as maternal transcripts and expressed until 24 hpf (hours post-fertilization), cyp11a2 expression starts at $32 \mathrm{hpf}$ (Parajes et al. 2013). This enzyme is essential for GC synthesis in larvae as well as for interrenal and gonadal steroidogenesis in adults (Li et al. 2020). Adult homozygous mutants are sterile and have disorganized testis and spermatogenesis as well as a significant reduction of male sex steroid production. However since its paralogue gene cyp11a1 is present and active at least during early development an analysis of a possible genetic compensation could be an interesting issue to focus on.

The last P450 enzyme involved in cortisol synthesis is Cyp11c1, whose KO was performed both in zebrafish and in Nile tilapia (Oreochromis niloticus) (Zhang et al. 2020, Zheng et al. 2020). Since this enzyme is required for the synthesis of both cortisol and 11-ketotestosterone, these two mutants show delayed spermatogenesis, reduced sperm production and alteration of testis morphology. Notably, the spermatogenesis-related phenotype is rescued by treatment with 11-ketotestosterone in both species. Spermatogenesis is naturally recovered in the Nile tilapia at 6 months post-fertilization, probably by the compensatory activity of testosterone whose serum concentration increases in these mutants (Zheng et al. 2020). Moreover, analysis of female reproduction confirms the role of cortisol on zebrafish oocyte maturation and ovulation (Zhang et al. 2020), already shown in the gria30/ia30 mutant line.

\section{Conclusions and future directions}

The review by Schaaf et al., published in 2009, while underlining the potentiality of zebrafish for GC and $\mathrm{Gr}$ research, also described the restricted number of tools available at that time (Schaaf et al. 2009).

Now this problem seems to be somehow solved with the application of MO knockdown on $g r$ expression, the generation of specific transgenic zebrafish reporter lines and, more recently, the availability of a great number of new $g r$ as well as other GC-related mutant lines. These advances have promoted, in a limited amount of time, an exponential growth of the scientific results obtained with this animal model, hence, increasing significantly our knowledge about GC biology.

Morpholino knockdown of zebrafish $g r$ revealed that the GC/Gr complex regulates the development of many structures and processes like mesoderm formation and heart development (Nesan et al. 2012, Wilson et al. 2015), BMP signaling pathway (Nesan \& Vijayan 2012, 2013), behavior and growth (Wilson et al. 2016). Furthermore, maternal $g r$ transcripts have been proven to have a pivotal role in the correct larval development while zygotic $g r$ 
mRNA seems to exert a limited contribution (Pikulkaew et al. 2011). This result highlights the importance of a correct concentration of maternal cortisol during development, not only in zebrafish but also in humans (Moisiadis \& Matthews 2014), and how zebrafish can be a useful model for the study of negative effects caused by either positive or negative variations of this hormone.

Ion balance was also investigated in zebrafish $g r$ morphants confirming the fundamental role of Gr rather than $\mathrm{Mr}$ in both ionocyte differentiation as well as transcription of ion channels and cotransporters (Lin et al. 2011, Cruz et al. 2013, Kumai et al. 2012).

Living biosensors for $\mathrm{Gr}$ transcriptional activity with different and specific features have been generated and used to analyze in vivo the alteration of $\mathrm{GC} / \mathrm{Gr}$ transcriptional activity in different conditions, or to screen for molecules able to interfere with GC signaling (Weger et al. 2012, Benato et al. 2014, Krug et al. 2014).

The first zebrafish $g r$ mutant line, identified by screening of a mutant library, was the $g^{53357 / 3357}$ line. In this zebrafish line, widely used in particular to study zebrafish neurobiology and behavior linked to GC activities, a missense mutation abolishes any DNA dependent transcriptional activity of Gr (Ziv et al. 2013).

However, the most prominent advance in GC research came after application of genome editing approaches to obtain null $g r$ mutant lines. In the last 3 years, many research groups generated $g r$ mutant zebrafish lines and applied them to improve our knowledge on many of the physiological processes in which these steroids are involved, and to elucidate the different roles played by $\mathrm{Gr}$ and $\mathrm{Mr}$ (Fig. 4). It is worth noting that $g r$ morphants show a slightly more severe phenotype compared with mutants. This result, widely discussed in Rossi et al. (2015) and in Eve et al. (2017), can be due to several causes such as off-target effects of MOs that can worsen morphant larvae phenotype or by the activation, in mutants but not in morphants, of genetic compensation mechanisms mediated by the transcriptional activation of paralog genes. Interestingly, a recent publication by El-Brolosy et al. (2019) revealed that in murine and zebrafish mutants the degradation of mutated transcripts by means of RNA decay triggers a transcriptional adaptation. Instead, mutants unable to degrade mutated mRNAs display a stronger phenotype.

The activation of genetic compensation, by allowing the achievement of adult life, gives the possibility to study the effects of gene silencing on adult organisms and, last but not least, it enables the analysis of alternative pathways useful in the search for new therapies.

\section{Declaration of interest}

The authors declare that there is no conflict of interest that could be perceived as prejudicing the impartiality of this review.

\section{Funding}

F A and N T are supported by AIRC grant IG 2017-19928, European Union Grant ZF-HEALTH CT-2010-242048, and Telethon grant GGP19287. L D V is supported by University of Padova grant 'Progetti di Ricerca di Ateneo CPDA134095'. A D and M C F are supported by a PhD fellowship from Ministero dell'Università e della Ricerca Scientifica e Tecnologica.

\section{Author contribution statement}

A Dinarello, G Licciardello, F Argenton and L Dalla Valle contributed equally.

\section{Acknowledgement}

Images were created with BioRender.com. We would like to thank Prof. Colombo, our great PhD mentor, for critical reading of the manuscript and for inspiring basic research on steroids at the University of Padua.

\section{References}

Alsop D \& Vijayan MM 2008 Development of the corticosteroid stress axis and receptor expression in zebrafish. American Journal of Physiology: Regulatory, Integrative and Comparative Physiology 294 R711-R719. (https://doi.org/10.1152/ajpregu.00671.2007)

Alsop D \& Vijayan MM 2009 The zebrafish stress axis: molecular fallout from the teleost-specific genome duplication event. General and Comparative Endocrinology 161 62-66. (https://doi.org/10.1016/j. ygcen.2008.09.011)

Ambroggi F, Turiault M, Milet A, Deroche-Gamonet V, Parnaudeau S, Balado E, Barik J, Van Der Veen R, Maroteaux G, Lemberger T, et al. 2009 Stress and addiction: glucocorticoid receptor in dopaminoceptive neurons facilitates cocaine seeking. Nature Neuroscience 12 247-249. (https://doi.org/10.1038/nn.2282)

Azetsu Y, Chatani M, Dodo Y, Karakawa A, Sakai N, Negishi-Koga T \& Takami M 2019 Treatment with synthetic glucocorticoids impairs bone metabolism, as revealed by in vivo imaging of osteoblasts and osteoclasts in Medaka fish. Biomedicine and Pharmacotherapy 118 109101. (https://doi.org/10.1016/j.biopha.2019.109101)

Baker ME 2019 Steroid receptors and vertebrate evolution. Molecular and Cellular Endocrinology 496 110526. (https://doi.org/10.1016/j mce.2019.110526)

Baker ME \& Katsu Y 201730 YEARS OF THE MINERALOCORTICOID RECEPTOR: Evolution of the mineralocorticoid receptor: sequence, structure and function. Journal of Endocrinology 234 T1-T16. (https:// doi.org/10.1530/JOE-16-0661)

Balasubramanian S, Raghunath A \& Perumal E 2019 Role of epigenetics in zebrafish development. Gene $\mathbf{7 1 8}$ 144049. (https://doi.org/10.1016/j. gene.2019.144049)

Bambino K \& Chu J 2017 Zebrafish in toxicology and environmental health. Current Topics in Developmental Biology 124 331-367. (https:// doi.org/10.1016/bs.ctdb.2016.10.007)

Baumeister D, Lightman SL \& Pariante CM 2016 The HPA axis in the pathogenesis and treatment of depressive disorders: integrating clinical and molecular findings. Journal of Experimental Psychopathology 3 64-76. (https://doi.org/10.5127/pr.034413) 
Beato M \& Klug J 2000 Steroid hormone receptors: an update. Human Reproduction Update 6 225-236. (https://doi.org/10.1093/ humupd/6.3.225)

Benato F, Colletti E, Skobo T, Moro E, Colombo L, Argenton F \& Dalla Valle L 2014 A living biosensor model to dynamically trace glucocorticoid transcriptional activity during development and adult life in zebrafish. Molecular and Cellular Endocrinology 392 60-72. (https://doi.org/10.1016/j.mce.2014.04.015)

Binder EB 2009 The role of FKBP5, a co-chaperone of the glucocorticoid receptor in the pathogenesis and therapy of affective and anxiety disorders. Psychoneuroendocrinology 34 (Supplement 1) S186-S195. (https://doi.org/10.1016/j.psyneuen.2009.05.021)

Brady C, Denora M, Shannon I, Clark KJ \& Rich A 2017 Intestinal transit time and cortisol-mediated stress in zebrafish. Zebrafish 14 404-410. (https://doi.org/10.1089/zeb.2017.1440)

Brun NR, Van Hage P, Hunting ER, Haramis AG, Vink SC, Vijever MG, Schaaf MJM \& Tudorache C 2019 Polystyrene nanoplastics disrupt glucose metabolism and cortisol levels with a possible link to behavioural changes in larval zebrafish. Communications Biology 2 382. (https://doi.org/10.1038/s42003-019-0629-6)

Burns CM 2016 The history of cortisone discovery and development. Rheumatic Diseases Clinics of North America 42 1-14, vii. (https://doi. org/10.1016/j.rdc.2015.08.001)

Busada JT \& Cidlowski JA 2017 Mechanisms of glucocorticoid action during development. Current Topics in Developmental Biology 125 147-170. (https://doi.org/10.1016/bs.ctdb.2016.12.004)

Challet E 2019 The circadian regulation of food intake. Nature Reviews: Endocrinology 15 393-405. (https://doi.org/10.1038/s41574-019-0210-x)

Chang YF, Imam JS \& Wilkinson MF 2007 The nonsense-mediated decay RNA surveillance pathway. Annual Review of Biochemistry 76 51-74. (https://doi.org/10.1146/annurev.biochem.76.050106.093909)

Chatzopoulou A, Roy U, Meijer AH, Alia A, Spaink HP \& Schaaf MJM 2015 Transcriptional and metabolic effects of glucocorticoid receptor $\alpha$ and $\beta$ signaling in zebrafish. Endocrinology 156 1757-1769. (https:// doi.org/10.1210/en.2014-1941)

Chatzopoulou A, Heijmans JPM, Burgerhout E, Oskam N, Spaink HP, Meijer AH \& Schaaf MJM 2016 Glucocorticoid-induced attenuation of the inflammatory response in zebrafish. Endocrinology 157 2772-2784. (https://doi.org/10.1210/en.2015-2050)

Chatzopoulou A, Schoonheim PJ, Torraca V, Meijer AH, Spaink HP \& Schaaf MJM 2017 Functional analysis reveals no transcriptional role for the glucocorticoid receptor $\beta$-isoform in zebrafish. Molecular and Cellular Endocrinology 447 61-70. (https://doi.org/10.1016/j. mce.2017.02.036)

Chen S, Reichert S, Singh C, Oikonomou G, Rihel J \& Prober DA 2017 Light-dependent regulation of sleep and wake states by prokineticin 2 in zebrafish. Neuron 95 P153-P168. (https://doi.org/10.1016/j. neuron.2017.06.001)

Chiu CN, Rihel J, Lee DA, Singh C, Mosser EA, Chen S, Sapin V, Pham U, Engle J, Niles BJ, et al. 2016 A zebrafish genetic screening identifies neuromedin $\mathrm{U}$ as a regulator of sleep/wake states. Neuron $\mathbf{8 9}$ P842-P856. (https://doi.org/10.1016/j.neuron.2016.01.007)

Cole TJ, Blendy JA, Monaghan AP, Krieglstein K, Schmid W, Aguzzi A, Fantuzzi G, Hummler E, Unsicker K \& Schütz G 1995 Targeted disruption of the glucocorticoid receptor gene blocks adrenergic chromaffin cell development and severely retards lung maturation. Genes and Development 9 1608-1621. (https://doi.org/10.1101/ gad.9.13.1608)

Colombo L, Dalla Valle L, Fiore C, Armanini D \& Belvedere P 2006 Aldosterone and the conquest of land. Journal of Endocrinological Investigation 29 373-379. (https://doi.org/10.1007/BF03344112)

Cruz SA, Lin CH, Chao PL \& Hwang PP 2013 Glucocorticoid receptor, but not mineralocorticoid receptor, mediates cortisol regulation of epidermal ionocyte development and ion transport in zebrafish (Danio rerio). PLOS ONE 8 e77997. (https://doi.org/10.1371/journal. pone.0077997)
Daneri-Becerra C, Zgajnar NR, Lotufo CM, Hyrb ABR, Piwien-Pilipuk G \& Galigniana MD 2019 Regulation of FKBP51 and FKBP52 functions by post-translational modifications. Biochemical Society Transactions 47 1815-1831. (https://doi.org/10.1042/BST20190334)

Dickmeis T, Lahiri K, Nica G, Vallone D, Santoriello C, Neumann CJ, Hammerschmidt M \& Foulkes NS 2007 Glucocorticoids play a role in circadian cell cycle rhythms. PLoS Biology 5 e78. (https://doi. org/10.1371/journal.pbio.0050078)

Eachus H, Zaucker A, Oakes JA, Griffin A, Weger M, Güran T, Taylor A, Harris A, Greenfield A, Quanson JL, et al. 2017 Genetic disruption of 21-hydroxylase in zebrafish causes interrenal hyperplasia. Endocrinology 158 4165-4173. (https://doi.org/10.1210/en.201700549)

Eberhardt W, Schulze M, Engels C, Klasmeier E \& Pfeilschifter J 2002 Glucocorticoid-mediated suppression of cytokine induced matrix metalloproteinase- 9 expression in rat mesangial cells: involvement of nuclear factor-kappaB and Ets transcription factors. Molecular Endocrinology 16 1752-1766. (https://doi.org/10.1210/me.20010278)

Eick GN \& Thornton JW 2011 Evolution of steroid receptors from an estrogen-sensitive ancestral receptor. Molecular and Cellular Endocrinology 334 31-38. (https://doi.org/10.1016/j.mce.2010.09.003)

El-Brolosy M, Kontarakis Z, Rossi A, Kuenne C, Günther S, Fujkuda N \& Kihki J, Boezio GLM, Takacs CM, Lai S, et al. 2019 Genetic compensation triggered by mutant mRNA degradation. Nature 568 193-197. (https://doi.org/10.1038/s41586-019-1064-z)

Eve AMJ, Place ES \& Smith JC 2017 Comparison of zebrafish tmem88a mutant and morpholino knockdown phenotypes. PLOS ONE 12 e0172227. (https://doi.org/10.1371/journal.pone.0172227)

Facchinello N, Skobo T, Meneghetti G, Colletti E, Dinarello A, Tiso N, Costa R, Gioacchini G, Carnevali O, Argenton F, et al. 2017 nr3c1 null mutant zebrafish are viable and reveal DNA-binding-independent activities of the glucocorticoid receptor. Scientific Reports $\mathbf{7} 4371$. (https://doi.org/10.1038/s41598-017-04535-6)

Fardet L, Petersen I \& Nazareth I 2012 Risk of cardiovascular events in people prescribed glucocorticoids with iatrogenic Cushing's syndrome: cohort study. BMJ 345 e4928. (https://doi.org/10.1136/ bmj.e4928)

Faught E \& Vijayan MM $2018 a$ The mineralocorticoid receptor is essential for stress axis regulation in zebrafish larvae. Scientific Reports $\mathbf{8} 18081$. (https://doi.org/10.1038/s41598-018-36681-w)

Faught E \& Vijayan MM $2018 b$ Maternal stress and fish reproduction: the role of cortisol revised. Fish and Fisheries 19 1016-1030. (https://doi. org/10.1111/faf.12309)

Faught E \& Vijayan MM 2019a Loss of the glucocorticoid receptor in zebrafish improves muscle glucose availability and increases growth American Journal of Physiology: Endocrinology and Metabolism 316 E1093-E1104. (https://doi.org/10.1152/ajpendo.00045.2019)

Faught E \& Vijayan MM $2019 b$ Postnatal triglyceride accumulation is regulated by mineralocorticoid receptor activation under basal and stress conditions. Journal of Physiology 597 4927-4941. (https://doi. org/10.1113/JP278088)

Faught E \& Vijayan MM 2020 Glucocorticoid and mineralocorticoid receptor activation modulates postnatal growth. Journal of Endocrinology 244 261-271. (https://doi.org/10.1530/JOE-19-0358)

Filosa A, Barker AJ, Dal Maschio M \& Baier H 2016 Feeding state modulates behavioral choice and processing of prey stimuli in the zebrafish tectum. Neuron 90 P596-P608. (https://doi.org/10.1016/j. neuron.2016.03.014)

Gans I, Hartig EI, Zhu S, Tilden AR, Hutchins LN, Maki NJ, Graber JH \& Coffman JA 2020 Klf9 is a key feedforward regulator of the transcriptomic response to glucocorticoid receptor activity. Scientific Reports 10 11415. (https://doi.org/10.1038/s41598-020-68040-z)

Garland MA, Sengupta S, Mathew LK, Truong L, De Jong E, Piersma AH, La Du J \& Tanguay RL 2019 Glucocorticoid receptor-dependent induction of cripto-1 (one-eyed pinhead) inhibits zebrafish caudal fin https://joe.bioscientifica.com https://doi.org/10.1530/JOE-20-0173 (c) 2020 Society for Endocrinology Published by Bioscientifica Ltd. Printed in Great Britain 
regeneration. Toxicology Reports 6 529-537. (https://doi.org/10.1016/j. toxrep.2019.05.013)

Geserick C, Meyer HA \& Haendler B 2005 The role of DNA response elements as allosteric modulators of steroid receptor function. Molecular and Cellular Endocrinology 236 1-7. (https://doi. org/10.1016/j.mce.2005.03.007)

Griffin A, Parajes S, Weger M, Zaucker A, Taylor AE, O'Neil DM, Müller F \& Krone N 2016 Ferredoxin 1b (Fdx1b) is the essential mitochondrial redox partner for cortisol biosynthesis in zebrafish. Endocrinology 157 1122-1134. (https://doi.org/10.1210/en.2015-1480)

Griffiths BB, Schoonheim PJ, Ziv L, Voelker L, Baier H \& Gathan E 2012 A zebrafish model of glucocorticoid resistance shows serotoninergic modulation of the stress response. Behavioral Neuroscience 668 . (https:/10.3389/fnbeh.2012.00068)

Groeneweg FL, Karst H, De Kloet ER \& Joëls M 2012 Mineralocorticoid and glucocorticoid receptors at the neuronal membrane, regulators of nongenomic corticosteroid signaling. Molecular and Cellular Endocrinology 350 299-309. (https://doi.org/10.1016/j. mce.2011.06.020)

Guh YJ \& Hwang PP 2017 Insight into molecular and cellular mechanisms of hormonal actions on fish ion regulation derived from the zebrafish model. General and Comparative Endocrinology 251 12-20. (https://doi.org/10.1016/j.ygcen.2016.08.009)

Hayward T, Young A, Jiang A, Crespi EJ \& Coffin AB 2019 Glucocorticoid receptor activation exacerbates aminoglycoside-induced damage to the zebrafish lateral line. Hearing Research 377 12-23. (https://doi. org/10.1016/j.heares.2019.03.002)

Hwang WY, Fu Y, Reyon D, Maeder ML, Tsai SQ, Sander JD, Peterson RT, Yeh JRJ \& Joung JK 2013 Efficient genome editing in zebrafish using a CRISPR-Cas system. Nature Biotechnology 31 227-229. (https://doi. org/10.1038/nbt.2501)

Jiang Y, Lu Y, Jiang X, Hu J, Li R, Liu Y, Zhu G \& Rong X 2020 Glucocorticoids induce osteoporosis mediated by glucocorticoid receptor-dependent and -independent pathways. Biomedicine and Pharmacotherapy 125 109979. (https://doi.org/10.1016/j. biopha.2020.109979)

Joëls M \& de Kloet ER 201730 YEARS OF THE MINERALOCORTICOID RECEPTOR: The brain mineralocorticoid receptor: a saga in three episodes. Journal of Endocrinology 234 T49-T66. (https://doi. org/10.1530/JOE-16-0660)

Kadmiel M \& Cidlowski JA 2013 Glucocorticoid receptor signaling in health and disease. Trends in Pharmacological Sciences 34 518-530. (https://doi.org/10.1016/j.tips.2013.07.003)

Kino T, Manoli I, Jelkar S, Wang Y, Su YA \& Chrousos GP 2009 Glucocorticoid receptor (GR) $\beta$ has intrinsic GR $\alpha$-independent transcriptional activity. Biochemical and Biophysical Research Communications 381 671-675. (https://doi.org/10.1016/j. bbrc.2009.02.110)

Krug RG, Poshusta TL, Skuster KJ, Berg MR, Gardner SL \& Clark KJ 2014 A transgenic zebrafish model for monitoring glucocorticoid receptor activity. Genes, Brain, and Behavior 13 478-487. (https://doi. org/10.1111/gbb.12135)

Kumai Y, Nesan D, Vijayan MM \& Perry SF 2012 Cortisol regulates $\mathrm{Na}^{+}$uptake in zebrafish, Danio rerio, larvae via the glucocorticoid receptor. Molecular and Cellular Endocrinology 364 113-125. (https:// doi.org/10.1016/j.mce.2012.08.017)

Kurrasch DM, Nevin LM, Wong JS, Baier H \& Ingraham HA 2009 Neuroendocrine transcriptional programs adapt dynamically to the supply and demand for neuropeptides as revealed in NSF mutant zebrafish. Neural Development 4 22. (https://doi.org/10.1186/17498104-4-22)

Kwan W, Cortes M, Frost I, Esain V, Theodore LN, Liu SY, Budrow N, Goessling W \& North TE 2016 The central nervous system regulates embryonic HSPC production via stress-responsive glucocorticoid receptor signaling. Cell Stem Cell 19 370-382. (https://doi. org/10.1016/j.stem.2016.06.004)
Kwong RWM \& Perry SF 2013 Cortisol regulates epithelial permeability and sodium losses in zebrafish exposed to acidic water. Journal of Endocrinology 217 253-264. (https://doi.org/10.1530/JOE-12-0574)

Lapp HE, Bartlett AA \& Hunter RG 2019 Stress and glucocorticoid receptor regulation of mitochondrial gene expression. Journal of Molecular Endocrinology 62 R121-R128. (https://doi.org/10.1530/JME-18-0152)

Lee HB, Schwab TL, Sigafoos AN, Gauerke JL, Krug RG, Serres MR, Jacobs DC, Cotter RP, Das B, Petersen MO, et al. 2019 Novel zebrafish behavioral assay to identify modifiers of the rapid, nongenomic stress response. Genes, Brain, and Behavior 18 e12549. (https://doi. org/10.1111/gbb.12549)

Lewis-Tuffin LJ, Jewell CM, Bienstock RJ, Collins JB \& Cidlowski JA 2007 Human glucocorticoid receptor $\beta$ binds RU-486 and is transcriptionally active. Molecular and Cellular Biology 27 2266-2282. (https://doi.org/10.1128/MCB.01439-06)

Li N, Oakes JA, Storbeck KH, Cunliffe VT \& Krone NP 2020 The P450 side-chain cleavage enzyme Cyp11a2 facilitates steroidogenesis in zebrafish. Journal of Endocrinology 244 309-321. (https://doi. org/10.1530/JOE-19-0384)

Lin CH, Tsai IL, Su CH, Tseng DY \& Hwang PP 2011 Reverse effect of mammalian hypocalcemic cortisol in Fish: cortisol stimulates $\mathrm{Ca}^{2+}$ uptake via glucocorticoid receptor-mediated vitamin $\mathrm{D}_{3}$ metabolism. PLOS ONE 6 e23689. (https://doi.org/10.1371/journal.pone.0023689)

Lin CH, Shih TH, Liu ST, Hsu HH \& Hwang PP 2015 Cortisol regulates acid secretion of $\mathrm{H}^{+}$-ATPase-rich ionocytes in zebrafish (Danio rerio) embryos. Frontiers in Physiology 6 328. (https://doi.org/10.3389/ fphys.2015.00328)

Lin CH, Hu HJ \& Huang PP 2016 Cortisol regulates sodium homeostasis by stimulating the transcription of sodium-chloride transporter (NCC) in zebrafish (Danio rerio). Molecular and Cellular Endocrinology 422 93-102. (https://doi.org/10.1016/j.mce.2015.12.001)

Lobert VH, Mouradov D \& Heath JK 2016 Focusing the spotlight on the zebrafish intestine to illuminate mechanisms of colorectal cancer. Advances in Experimental Medicine and Biology 916 411-437. (https:// doi.org/10.1007/978-3-319-30654-4_18)

Löhr H \& Hammerschmidt M 2011 Zebrafish in endocrine systems: recent advances and implications for human disease. Annual Review of Physiology 73 183-211. (https://doi.org/10.1146/annurevphysiol-012110-142320)

MacRae CA \& Peterson RT 2015 Zebrafish as tools for drug discovery. Nature Reviews: Drug Discovery 14 721-731. (https://doi.org/10.1038/ $\operatorname{nrd} 4627)$

Marchi D, Santhakumar K, Markham E, Li N, Storbeck KH, Krone N, Cunliffe VT \& Van Eeden FJM 2020 Bidirectional crosstalk between hypoxia-inducible factor and glucocorticoid signalling in zebrafish larvae. PLoS Genetics 16 e1008757. (https://doi.org/10.1371/journal. pgen.1008757)

Mathew LK, Sengupta S, Kawakami A, Andreasen EA, Löhr CV, Loynes CA, Renshaw SA, Peterson RT \& Tanguay RL 2007 Unraveling tissue regeneration pathways using chemical genetics. Journal of Biological Chemistry 282 35202-35210. (https://doi.org/10.1074/jbc. M706640200)

McGonnell IM \& Fowkes RC 2006 Fishing for gene function - endocrine modelling in the zebrafish. Journal of Endocrinology 189 425-439. (https://doi.org/10.1677/joe.1.06683)

Miller WL 2017 Steroidogenesis: unanswered questions. Trends in Endocrinology and Metabolism 28 771-793. (https://doi.org/10.1016/j. tem.2017.09.002)

Moisiadis VG \& Matthews SG 2014 Glucocorticoids and fetal programming part1: outcomes. Nature Reviews: Endocrinology 10 391-402. (https://doi.org/10.1038/nrendo.2014.73)

Morbiato E, Frigato E, Dinarello A, Maradonna F, Facchinello N, Argenton F, Carnevali O, Dalla Valle L \& Bertolucci C 2019 Feeding entrainment of the zebrafish circadian clock is regulated by the glucocorticoid receptor. Cells 8 1342. (https://doi.org/10.3390/ cells8111342) https://joe.bioscientifica.com

https://doi.org/10.1530/JOE-20-0173 (c) 2020 Society for Endocrinology Published by Bioscientifica Ltd. Printed in Great Britain 
Mosser EA, Chiu CN, Tamai TK, Hirota T, Li S, Hui M, Wang A, Singh C, Giovanni A, Kay SA, et al. 2019 Identification of pathways that regulate circadian rhythms using a larval zebrafish small molecule screen. Scientific Reports 9 12405. (https://doi.org/10.1038/s41598019-48914-7)

Muto A, Orger MB, Wehman AM, Smear MC, Kay JN, Page-McCaw PS, Gathan E, Xiao T, Nevin LM, Gosse NJ, et al. 2005 Forward genetic analysis of visual behavior in zebrafish. PLoS Genetics 1 e66. (https:// doi.org/10.1371/journal.pgen.0010066)

Muto A, Taylor MR, Suzawa M, Korenbrot JI \& Baier H 2013 Glucocorticoid receptor activity regulates light adaptation in the zebrafish retina. Frontiers in Neural Circuits 7 145. (https://doi. org/10.3389/fncir.2013.00145)

Napier C \& Pearce SHS 2014 Current and emerging therapies for Addison's disease. Current Opinion in Endocrinology, Diabetes, and Obesity 21 147-153. (https://doi.org/10.1097/ MED.0000000000000067)

Nelson CM, Lennon VA, Lee H, Krug RG, Kamalova A, Madigan NN, Clark KJ, Windebank AJ \& Henley JR 2019 Glucocorticoids target ependymal glia and inhibit repair of the injured spinal cord. Frontiers in Cell and Developmental Biology 7 56. (https://doi.org/10.3389/ fcell.2019.00056)

Nesan D \& Vijayan MM 2012 Embryo exposure to elevated cortisol level leads to cardiac performance dysfunction in zebrafish. Molecular and Cellular Endocrinology 363 85-91. (https://doi.org/10.1016/j. mce.2012.07.010)

Nesan D \& Vijayan MM 2013 The transcriptomics of glucocorticoid receptor signaling in developing zebrafish. PLOS ONE $\mathbf{8}$ e80726. (https://doi.org/10.1371/journal.pone.0080726)

Nesan D, Kamkar M, Burrows J, Scott IC, Marsden M \& Vijayan MM 2012 Glucocorticoid receptor signaling is essential for mesoderm formation and muscle development in zebrafish. Endocrinology 153 1288-1300. (https://doi.org/10.1210/en.2011-1559)

Nicolaides NC, Galata Z, Kino T, Chrousos GP \& Charmandari E 2010 The human glucocorticoid receptor: molecular basis of biologic function. Steroids $\mathbf{7 5}$ 1-12. (https://doi.org/10.1016/j. steroids.2009.09.002)

Oakes JA, Li N, Wistow BRC, Griffin A, Barnard L, Storbeck KH, Cunliffe VT \& Krone NP 2019 Ferredoxin 1b deficiency leads to testis disorganization, impaired spermatogenesis and feminization in zebrafish. Endocrinology 160 2401-2416. (https://doi.org/10.1210/ en.2019-00068)

Oakley RH \& Cidlowski JA 2013 The biology of the glucocorticoid receptor: new signaling mechanisms in health and disease. Journal of Allergy and Clinical Immunology 132 1033-1044. (https://doi. org/10.1016/j.jaci.2013.09.007)

Ohhira S, Watanabe M \& Matsui H 2003 Metabolism of tributyltin and triphenyltin by rat, hamster and human hepatic microsomes. Archives of Toxicology 77 138-144. (https://doi.org/10.1007/s00204-002-0428-5)

Palstra AP, Mendez S, Dirks RP \& Schaaf MJM 2019 Cortisol acting through the glucocorticoid receptor is not involved in exerciseenhanced growth, but does affect the white skeletal muscle transcriptome in zebrafish (Danio rerio). Frontiers in Physiology 91889 (https://doi.org/10.3389/fphys.2018.01889)

Parajes S, Griffin A, Taylor AE, Rose IT, Miguel-Escalada I, Hadzev Y, Arlt W, Shackleton C, Müller F \& Krone N 2013 Redefining the initiation and maintenance of zebrafish interrenal steroidogenesis by characterizing the key enzyme Cyp11a2. Endocrinology 154 2702-2711. (https://doi.org/10.1210/en.2013-1145)

Pikulkaew S, De Nadai A, Belvedere P, Colombo L \& Dalla Valle L 2010 Expression analysis of steroid hormone receptor mRNAs during zebrafish embryogenesis. General and Comparative Endocrinology 165 215-220. (https://doi.org/10.1016/j.ygcen.2009.06.024)

Pikulkaew S, Benato F, Celeghin A, Zucal C, Skobo T, Colombo L \& Dalla Valle L 2011 The knockdown of maternal glucocorticoid receptor
mRNA alters embryo development in zebrafish. Developmental Dynamics 240 874-889. (https://doi.org/10.1002/dvdy.22586)

Pippal JB, Cheung CMI, Yao YZ, Brennan FE \& Fuller PJ 2011 Characterization of the zebrafish mineralocorticoid receptor. Molecular and Cellular Endocrinology 332 58-66. (https://doi.org/10.1016/j. mce.2010.09.014)

Quax RA, Manenschijn L, Koper JW, Hazes JM, Lamberts SWJ, Van Rossum EFC \& Feelder RA 2013 Glucocorticoid sensitivity in health and disease. Nature Reviews: Endocrinology 9 670-686. (https://doi. org/10.1038/nrendo.2013.183)

Ratman D, Berghe WV, Dejager L, Libert C, Tavernier J, Beck IM \& De Bosscher K 2013 How glucocorticoid receptors modulate the activity of other transcription factors: a scope beyond tethering. Molecular and Cellular Endocrinology 380 41-54. (https://doi.org/10.1016/j. mce.2012.12.014)

Rossi A, Kontarakis Z, Gerri C, Nolte H, Hölper S, Krüger M \& Stainier DY 2015 Genetic compensation induced by deleterious mutations but not gene knockdowns. Nature $\mathbf{5 2 4} 230-233$. (https://doi.org/10.1038/ nature14580)

Sakamoto T, Yoshiki M, Takahashi H, Yoshida M, Ogino Y, Ikeuchi T, Nakamachi T, Konno N, Matsuda K \& Sakamoto H 2016 Principal function of mineralocorticoid signaling suggested by constitutive knockout of the mineralocorticoid receptor in medaka fish. Scientific Reports 6 37991. (https://doi.org/10.1038/srep37991)

Sakamoto T, Yoshiki M \& Sakamoto H 2017 The mineralocorticoid receptor knockout in medaka is further validated by glucocorticoid receptor compensation. Scientific Data 4 170189. (https://doi. org/10.1038/sdata.2017.189)

Sallin P \& Jaźwińska A 2016 Acute stress is detrimental to heart regeneration in zebrafish. Open Biology 6 160012. (https://doi. org/10.1098/rsob.160012)

Schaaf MJM, Champagne D, Van Laanen IHC, Van Wijk DCWA, Meijer AH, Meijer OC, Spaink HP \& Richardson MK 2008 Discovery of a functional glucocorticoid receptor $\beta$-isoform in zebrafish. Endocrinology 149 1591-1599. (https://doi.org/10.1210/en.2007-1364)

Schaaf MJM, Chatzopoulou A \& Spaink HP 2009 The zebrafish as a model system for glucocorticoid receptor research. Comparative Biochemistry and Physiology: Part A, Molecular and Integrative Physiology 153 75-82. (https://doi.org/10.1016/j.cbpa.2008.12.014)

Schaeffer C, Izzi C, Vettori A, Pasqualetto E, Cittaro D, Lazarevic D, Caridi G, Gnutti B, Mazza C, Jovine L, et al. 2019 Autosomal dominant tubulointerstitial kidney disease with adult onset due to a novel renin mutation mapping in the mature protein. Scientific Reports 9 11601. (https://doi.org/10.1038/s41598-019-48014-6)

Scheschowitsch K, Leite JA \& Assreuy J 2017 New insights in glucocorticoid receptor signaling - more than just a ligand-binding receptor. Frontiers in Endocrinology 8 16. (https://doi.org/10.3389/ fendo.2017.00016)

Schmid W, Cole TJ, Blendy JA \& Schütz G 1995 Molecular genetic analysis of glucocorticoid signaling in development. Journal of Steroid Biochemistry and Molecular Biology 53 33-35. (https://doi. org/10.1016/0960-0760(95)00038-2)

Sengupta S, Bisson WH, Mathew LK, Kolluri SK \& Tanguay RL 2012 Alternate glucocorticoid receptor ligand binding structures influence outcomes in an in vivo tissue regeneration model. Comparative Biochemistry and Physiology: Toxicology and Pharmacology 156 121-129. (https://doi.org/10.1016/j.cbpc.2012.05.003)

Severson TM, Kim Y, Joosten SEP, Schuurman K, van der Groep P, Moelans CB, ter Hoeve ND, Manson QF, Martens JW, van Deurzen CHM, et al. 2018 Characterizing steroid hormone receptor chromatin binding landscapes in male and female breast cancer. Nature Communications 9 482. (https://doi.org/10.1038/s41467-01802856-2)

Silverman MN \& Sternberg EM 2012 Glucocorticoid regulation of inflammation and its functional correlates: from HPA axis to https://joe.bioscientifica.com

https://doi.org/10.1530/JOE-20-0173 (c) 2020 Society for Endocrinology Published by Bioscientifica Ltd. Printed in Great Britain 
glucocorticoid receptor dysfunction. Annals of the New York Academy of Sciences 1261 55-63. (https://doi.org/10.1111/j.1749-6632.2012.06633.x)

Sireeni J, Bakker N, Jaikumar G, Obdam D, Slabbekoorn H, Tudorache C \& Schaaf M 2020 Profound effects of glucocorticoid resistance on anxiety-related behavior in zebrafish adults but not in larvae. General and Comparative Endocrinology 292 113461. (https://doi.org/10.1016/j. ygcen.2020.113461)

Spulber S, Raciti M, Dulko-Smith B, Lupu D, Rüegg J, Nam K \& Ceccatelli S 2018 Methylmercury interferes with glucocorticoid receptor: potential role in the mediation of developmental neurotoxicity. Toxicology and Applied Pharmacology 354 94-100. (https://doi.org/10.1016/j.taap.2018.02.021)

Stainier DYR, Raz E, Lawson ND, Ekker SC, Burdin RD, Eisen JS, Ingham PW, Schulte-Merker S, Yelon D, Weinstein BM, et al. 2017 Guidelines for morpholino use in zebrafish. PLoS Genetics $\mathbf{1 3}$ e1007000. (https://doi.org/10.1371/journal.pgen.1007000)

Taves MD, Gomez-Sanchez CE \& Soma KK 2011 Extra-adrenal glucocorticoids and mineralocorticoids: evidence for local synthesis, regulation and function. American Journal of Physiology: Endocrinology and Metabolism 301 E11-E24. (https://doi.org/10.1152/ ajpendo.00100.2011)

Tokarz J, Möller G, De Angelis MH \& Adamski J 2015 Steroids in teleost fishes: a functional point of view. Steroids 103 123-144. (https://doi. org/10.1016/j.steroids.2015.06.011)

Tronche F, Kelledonk C, Kretz O, Gass P, Anlag K, Orban PC, Bock R, Klein R \& Schütz G 1999 Disruption of the glucocorticoid receptor gene in the nervous system results in reduced anxiety. Nature Genetics 23 99-103. (https://doi.org/10.1038/12703)

Tsachaki M, Meyer A, Weger B, Kratschmar DV, Tokar J, Adamski J, Belting HG, Affolter M, Dickmeis T \& Odermatt A 2017 Absence of 11-keto reduction of cortisone and 11-ketotestosterone in the model organism zebrafish. Journal of Endocrinology 232 323-335. (https://doi. org/10.1530/JOE-16-0495)

Tuckermann JP, Reichardt HM, Arribas R, Richter KH, Schütz G \& Angel P 1999 The DNA binding-independent function of the glucocorticoid receptor mediates repression of AP-1-dependent genes in skin. Journal of Cell Biology 147 1365-1370. (https://doi.org/10.1083/jcb.147.7.1365)

van Weert LTCM, Buurstede JC, Mahfouz A, Braakhuis PSM, Polman JAE, Sips HCM, Roosendaal B, Balog J, de Kloet ER, Datson NA, et al. 2017 NeuroD factors discriminate mineralocorticoid from glucocorticoid receptor DNA binding in male rat brain. Endocrinology 158 1511-1522. (https://doi.org/10.1210/en.2016-1422)

Veras Ribeiro Filho H, Tambones IL, Mariano Gonçalves Dias M, Bernardi Videira N, Bruder M, Amorim Amato A \& Migliorini Figueira AC 2019 Modulation of nuclear receptor function: targeting the protein-DNA interface. Molecular and Cellular Endocrinology 484 1-14. (https://doi. org/10.1016/j.mce.2019.01.023)

Vettori A, Greenald D, Wilson GK, Peron M, Facchinello N, Markham E, Sinnakaruppan M, Matthews LC, McKeating JA, Argenton F, et al. 2017 Glucocorticoids promote von Hippel Lindau degradation and
HIF-1 $\alpha$ stabilization. PNAS 114 9948-9953. (https://doi.org/10.1073/ pnas.1705338114)

Volff JN 2005 Genome evolution and biodiversity in teleost fish. Heredity 94 280-294. (https://doi.org/10.1038/sj.hdy.6800635)

Weger BD, Weger M, Nusser M, Brenner-Weiss G \& Dickmeis T 2012 A chemical screening system for glucocorticoid stress hormone signaling in an intact vertebrate. ACS Chemical Biology 7 1178-1183. (https://doi.org/10.1021/cb3000474)

Weger BD, Weger M, Jung N, Lederer C, Bräse S \& Dickmeis T 2013 A chemical screening procedure for glucocorticoid signaling with a zebrafish larva luciferase reporter system. Journal of Visualized Experiments 79 50439. (https://doi.org/10.3791/50439)

Weger M, Weger BD, Görling B, Poschet G, Yildiz M, Hell R, Luy B, Akcay T, Güran T, Dickmeis T, et al. 2018 Glucocorticoid deficiency causes transcriptional and post-transcriptional reprogramming of glutamine metabolism. EBioMedicine 36 376-389. (https://doi. org/10.1016/j.ebiom.2018.09.024)

Whirledge S \& Cidlowski JA 2017 Glucocorticoids and Reproduction: traffic control on the road to reproduction. Trends in Endocrinology and Metabolism 28 399-415. (https://doi.org/10.1016/j. tem.2017.02.005)

Whirledge S \& DeFranco DB 2018 Glucocorticoid Signaling in health and disease: insights from tissue-specific GR knockout mice. Endocrinology 159 46-64. (https://doi.org/10.1210/en.2017-00728)

Wilson KS, Baily J, Tucker CS, Matrone G, Vass S, Moran C, Chapman KE, Mullins JJ, Kenyon C, Hadoke PWF, et al. 2015 Early-life perturbations in glucocorticoid activity impacts on the structure, function and molecular composition of the adult zebrafish (Danio rerio) heart. Molecular and Cellular Endocrinology 414 120-131. (https://doi. org/10.1016/j.mce.2015.07.025)

Wilson KS, Tucker CS, Al-Dujaili EAS, Holmes MC, Hadoke PWF, Kenyon CJ \& Denvir MA 2016 Early-life glucocorticoids programme behaviour and metabolism in adulthood in zebrafish. Journal of Endocrinology 230 125-142. (https://doi.org/10.1530/JOE-15-0376)

Yasir M, Amandeep G, Pankaj B \& Sidharth S 2020 Corticosteroids adverse effects. In StatPearls. Treasure Island, FL, USA: Statpearl Publishing. (available at: https://www.ncbi.nlm.nih.gov/books/ NBK531462/)

Zhang Q, Ye D, Wang H, Wang Y, Hu W \& Sun Y 2020 Zebrafish cyp11c1 knockout reveals the roles of 11-ketotestosterone and cortisol in sexual development and reproduction. Endocrinology 161 bqaa048. (https://doi.org/10.1210/endocr/bqaa048)

Zheng Q, Xiao H, Shi H, Wang T, Sun L, Tao W, Kocher TD, Li M \& Wang D 2020 Loss of Cyp11c1 causes delayed spermatogenesis due to the absence of 11-ketotestosterone. Journal of Endocrinology $\mathbf{2 4 4}$ 487-499. (https://doi.org/10.1530/JOE-19-0438)

Ziv L, Muto A, Schoonheim PJ, Meijsing SH, Strasser D, Ingraham HA, Schaaf MJM, Yamamoto KR \& Baier H 2013 An affective disorder in zebrafish with mutation of the glucocorticoid receptor. Molecular Psychiatry 18 681-691. (https://doi.org/10.1038/mp.2012.64)

Received in final form 10 August 2020

Accepted 15 September 2020

Accepted Manuscript published online 15 September 2020 https://joe.bioscientifica.com https://doi.org/10.1530/JOE-20-0173 (c) 2020 Society for Endocrinology Published by Bioscientifica Ltd. Printed in Great Britain 